\title{
Recent progress in cellulose nanocrystals: sources and production
}

\author{
Djalal Trache ${ }^{a, *}$, M. Hazwan Hussin', M.K. Mohamad Haafiz ${ }^{\mathrm{c}}$, Vijay Kumar Thakur d,* \\ ${ }^{a}$ UER Chimie Appliquée, Ecole Militaire Polytechnique, BP 17, Bordj El-Bahri, Algiers, Algeria. \\ ${ }^{b}$ Lignocellulosic Research Group, School of Chemical Sciences, Universiti Sains Malaysia, 11800 Minden, \\ Penang, Malaysia. \\ ${ }^{c}$ School of Industrial Technology, Universiti Sains Malaysia, 11800 Minden, Penang, Malaysia. \\ ${ }^{d}$ Enhanced Composites and Structures Center, School of Aerospace, Transport and Manufacturing, Cranfield \\ University, Bedfordshire MK43 OAL, UK \\ ${ }^{*}$ Corresponding authors \\ E-mail Addresses: djalaltrache@gmail.com,Vijay.Kumar@cranfield.ac.uk \\ Tel: +213 661808275, Fax: +213 21863204
}

\section{Abstract:}

Cellulose nanocrystals, a class of fascinating bio-based nanoscale materials, have received a tremendous amount of interest both in industry and academia owing to its unique structural features and impressive physicochemical properties such as biocompatibility, biodegradability, renewability, low density, adaptable surface chemistry, optical transparency, and improved mechanical properties. This nanomaterial is a promising candidate for applications in fields such as biomedical, pharmaceuticals, electronics, barrier films, nanocomposites, membranes, supercapacitors, etc. New resources, new extraction procedures, and new treatments are currently under development to satisfy the increasing demand of manufacturing new types of cellulose nanocrystals-based materials on an industrial scale. Therefore, this review addresses the recent progress in the production methodologies of cellulose nanocrystals, covering principal cellulose resources and the main processes used for its isolation. A critical and analytical examination of the shortcomings of various approaches employed so far is made. Additionally, structural organization of cellulose and nomenclature of cellulose nanomaterials have also been discussed for beginners in this field.

Keywords: cellulose nanocrystals, natural resources, pretreatments, isolation processes 


\section{Introduction}

The emergence and development of nanotechnology, a field expected to revolutionize several aspects of human life, offer a new approach to education, learning, innovation and governance. Currently, the disciplines of nanoscience and nanotechnology have been emphasized for exceptional focuses by various funding agencies and governments ${ }^{1,2}$. In 2009 , the worldwide market for products incorporating nanotechnology was found to be attained a value of about USD 254 billion and this number was expected to double each 3 years until 2020, when this value could reach USD 3 trillion ${ }^{3,4}$. Ever since the successful production of nanocrystalline materials by Gleiter in the $1980 \mathrm{~s}^{5}$, nanomaterials have seen a rapid development having wide range of applications in chemistry, physics, catalysis, material science, biomedical science, etc. ${ }^{6}$. Seeing the current emphasis on green chemistry and chemical processes, the application of the fundamental principles of green chemistry to nanotechnology and nanomaterials may extend their appeal to consumers and open up new markets for renewable materials for advanced applications. Indeed, materials from bio-based resources have attracted immense research interest in recent years as a result of their very high potentials for fabricating several high-value products with low impact on the environment ${ }^{7-14}$. Effective utilization of various nature-based nanomaterials offers certain ecological advantages, extraordinary physicochemical properties and high performance to name a few. However, full employment of the intrinsic properties of starting nanoscale materials necessitates continuous development of robust and versatile isolation, synthetic and processing procedures to well control assembly over a variety of length scales.

Among various natural materials, cellulose holds a crucial position in abundant organic raw materials. It is considered as a virtual inexhaustible source of feedstock meeting the increasing demand for green and biocompatible products ${ }^{13,15,16}$. Exploitation of cellulose has been known since the beginning of civilization, from clothes and paper to use as construction 
materials, yet over the last few decades, it has attracted much attention and growing interest owing to its abundancy and versatility when processing on the nanoscale in the form of cellulose nanomaterials 3, 8, 17-25. Employing various reaction strategies, different types of nanomaterials can be extracted from cellulose owing to its hierarchical structure and semicrystalline nature ${ }^{20,21,25}$. One of the most recent robust trend, on an international scale, is to extensively focus on the extraction of nanostructured materials and nanofibers of cellulose with dimensions in tens of nanometer and to employ their improved properties to develop innovative high value materials with new and advanced functionalities. Several forms of such cellulose nanomaterials can be prepared using various routes and from different cellulose sources $^{3,26-32}$.

Recently, highly crystalline nanoscale material, namely cellulose nanocrystals (CNCs), has garnered tremendous level of attention from many research communities 3, 11, 22, 33-36, which can be confirmed by the increasing number of scientific publications in the field over the past decade, as shown in Fig. 1. CNCs are broadly needle-shaped nanometric or rod like particles having at least one dimension $<100 \mathrm{~nm}$, and exhibit a highly crystalline nature. They can be produced from diverse starting materials that include algal cellulose, bacterial cellulose, bast fibers, cotton linters, microcrystalline cellulose, tunicin, and wood pulp ${ }^{3,8,11,22,33-42}$. These nanocrystals impart attractive combinations of biophysicochemical characteristics such as biocompatibility, biodegradability, light weight, non-toxicity, stiffness, renewability, sustainability, optical transparency, low thermal expansion, gas impermeability, adaptable surface chemistry, and improved mechanical properties ${ }^{43,44}$. These nanocrystals can also substitute some petrochemical-based products and are more economic than the similar high performance nanomaterials. Variations in the CNCs extraction process lead mainly to different CNCs properties. One of the main shortcomings concerning the employment of CNCs in commercial applications is related to their efficient fabrication at affordable quantity 
and quality. Acid hydrolysis is one of the most frequently used technique to prepare $\mathrm{CNCs}$ from various cellulose based starting materials and employs strong acids namely sulfuric and hydrochloric acids 11, 22, 23, 25, 35. Recently, other mineral and organic acids have also been utilized to produce $\mathrm{CNCs}{ }^{8}, 38,39,45-47$. Several other preparations approaches have been developed, such as enzymatic hydrolysis ${ }^{48-51}$, mechanical refining ${ }^{52-54}$, ionic liquid treatment 48-51, 55-58, subcritical water hydrolysis ${ }^{32,59}$, oxidation method ${ }^{60-63}$ and combined processes ${ }^{64-}$ 68. Keeping in mind the different synthesis strategies, one of the prime objectives of this review is to summarize and emphasize the up-to-date procedures employed to extract $\mathrm{CNCs}$ showing their advantages and drawbacks, that we believe will provide a strong base for the future development in this emerging area of research.

Among various materials, functional nanomaterials are of particular importance as they permit the formation of novel materials with new or enhanced properties by combining multiple ingredients and exploiting synergistic effects, such as physicochemical, catalytic, selective permeation, electronic, mechanical, optical, magnetic, or bioactivity, adsorption, etc. With a special functionality or numerous remarkable functions, functional nanomaterials present an imperative class of materials having high potential for advanced applications. To expand the application fields of CNCs, various approaches have been used to improve the interface properties ${ }^{23}$. Previously various covalent/ non-covalent chemical modification techniques have been used to develop new surface modified CNCs with outstanding properties $^{69-71}$. One of the procedure is to covalently graft hydrophobic molecules through reactions with hydroxyl groups on the CNCs surface, such as esterification, acetylation, silylation, and polymer grafting. Another approach is to utilize non-covalent interactions by incorporating compatibilizing agents into composites, including surfactants, polymers, and counter ion salts. 
The production of CNCs and their surface modifications have become one of the most intensely investigated areas of $\mathrm{CNCs}$ research on nanocomposites, since this nanoscale material offers a unique combination of high physicochemical properties even at low filler content, environmental benefits, and can surpass other candidates such as Kevlar, Boron nanowhiskers, carbon nanotube, and carbon fibers, as shown in Table 1. However, most of them are not biodegradable, and during the past couple of decades, the interest for nanomaterials derived from renewable sources has increased ${ }^{72}$. CNCs display intrinsically high aspect ratios and large surface area owing to their nanoscale size that renders them ideal candidates for nanocomposites. Specifically, greater interfacial area and strong interactions among the reinforcing filler and the polymer matrix are known to give rise to nanoconfinement effects that enable substantial improvement of mechanical properties. Nanocomposites reinforced with $\mathrm{CNCs}$ have reliably showed good properties including multifold increase in the elastic modulus and significant shifts in glass transition, while at the same time preserving excellent optical properties of the host polymer and contributing to requires the manufacturing of products and materials that have the capability to surpass the current academic and industrial expectations. Whether it is for automotive, medicine, building, marine, or aerospace, such materials must possess advanced performances, lower pharmaceuticals, drug delivery, templates for electronic components, fibers and textiles, separation membranes, supercapacitors, batteries, and electroactive polymers, among many

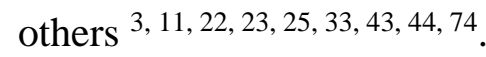


Several reviews $3,11,13,19,22-25,33-36,43,44,69,75-81$, books ${ }^{8,12,20,42,82,83}$ and patents ${ }^{21}$ have been published in the last two decades covering various aspects related to CNCs, including isolation processes, characterization, chemical modification of surfaces, self-assembly of suspensions, CNCs-containing nanocomposites and processing.

However, the focus of the current article is different from the published literature and where appropriate, specific points covered in published literature are summarized and/or referenced out to the corresponding paper/book/patent. This review firstly provides an overview on the recent research developments on principal cellulose sources followed by the main procedures used for its isolation in details. The extraction methodologies of CNCs are considered and discussed as well. In addition, we have also provided a critical and analytical examination of the shortcomings of various approaches employed so far.

\section{Structural organization of cellulose}

Cellulose (a carbohydrate polymer) is the most abundant renewable polymer in nature and represents about fifty percent of natural biomass having an yearly production estimated around 10 tons ${ }^{11,71}$. A number of review articles have already summarized the state of current knowledge on this fascinating and innovative polymer ${ }^{8,11,15,22,25,84}$. Broadly, cellulose is a fibrous, tough, water-insoluble substance that plays a crucial role in preserving the structure of natural fibers. Cellulose $\left(\left(\mathrm{C}_{6} \mathrm{H}_{10} \mathrm{O}_{5}\right)_{n} ; n=10000\right.$ to 15000 , where $n$ is depended on the cellulose source material) is defined as long polymer chain of ringed glucose molecules and has a flat ribbon-like conformation ${ }^{20,85}$. It is a linear natural polymer consisting of $1,4-$ anhydro-D-glucopyranose units as depicted in Fig. 2. Through natural synthesis, the cellulose does not exist as an individual entity but several chains of cellulose molecules (30 to 100 chains) could be packed together during extended chain conformation via van der Waals forces and hydrogen bonds to form the basic unit of cellulose fibers, which are elementary fibrils (protofibrils) at nano-scale $22,33,86$. These protofibrils are further gathered by 
intermolecular and intramolecular hydrogen bonding into the hierarchical microstructures, which usually recognized as microfibrils that display cross dimensions ranging from 2 to 20 $\mathrm{nm}{ }^{20,25}$. Depending on inter- and intramolecular interactions, molecular orientations, method of extraction and treatment, cellulose can exist as various polymorphs or allomorphs ${ }^{15,22,25}$.

As a result of the equatorial positions of hydroxyls, three hydroxyl groups $(\mathrm{OH})$ that protrude laterally along the cellulose chain have been reported to be easily available for $\mathrm{H}$ bonding ${ }^{11,25,33}$. The complex and strong network of H-bonds between the hydroxyl groups of cellulose chains can arrange and stabilize the cellulose molecules into a highly organized structure through crystalline packing. It gives rise to the structures with slender and nearly endless crystalline rods along the microfibril axis ${ }^{23,87}$. However, another part of cellulose molecules that could not be stabilized laterally through $\mathrm{H}$-bonding, would form disordered and less organized segments which are linked with cellulose crystals ${ }^{33}$. These amorphous domains are characterized with lower density in comparison to the crystalline parts and are easily available for bonding (e.g. hydrogen) with other molecules including water. On the application of an appropriate combination of chemical, enzymatic and mechanical treatments to these microfibrils, the highly crystalline domains of the cellulose microfibrils can be easily isolated that results in the formation of the desired cellulose nanocrystals ${ }^{34}$.

\section{Nomenclature of cellulose nanomaterials}

The development of cellulose nanomaterials has attracted great interest from both the academic and industrial world along with the standards community during the last couple of decades owing to the unique and potentially useful properties they endow such as high tensile strength, high Young's modulus, high surface area-to-volume ration and low coefficient of thermal expansion. This interest is well evident from the research papers published in this field as well as extensive number of patents on the work containing cellulose nanomaterials, as shown in Charreau review ${ }^{21}$. Cellulose nanomaterials (CNM) are considered as a type of 
nano-objects where the term nano-object is defined according to ISO publications as material with one, two or three external dimensions in the nanoscale ${ }^{88,89}$. CNM is a term often employed to describe nanoscale of a cellulosic material, which is considered to be in the nanoscale range if the fibril particle diameters or width is between 1 to $100 \mathrm{~nm}$. Fig. 3 illustrates the diverse hierarchical structure of cellulose nanomaterials. It is worth noting that

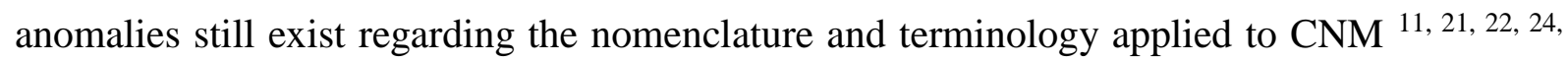
35, 90. Recently, the Technical Association of the Pulp and Paper Industry (TAPPI) has established a Nanotechnology Division devoted to the standardization of cellulose nanomaterials definitions. For the first nanomaterials standard (TAPPI WI 3021: Standard Terms and Their Definition for Cellulose Nanomaterials) a draft version has been prepared and comments on this standard are still under review ${ }^{91}$. The existing literature suggests that various terminologies have been and are currently employed to designate cellulose nanomaterials, which unfortunately leads to ambiguities and misunderstanding. Different terms have been used to refer to cellulose nanomaterial elements including cellulose nanofibers, nanoscale cellulose, cellulose microfibrils, cellulose nanofibrils, nanocellulose, nanocellulosic fibrils, cellulose nanoparticles, and nano-sized cellulose fibrils ${ }^{11,21,23,24,90}$. As shown in Fig. 3, nanoscale cellulose can be divided into nanostructured materials and nanofibers resulting from the use of various isolation processes ${ }^{3,21,90,92}$. These nanostructured materials procured from cellulose are generally categorized into microcrystalline cellulose (or cellulose microcrystals) and cellulose microfibrils (TAPPI WI 3021). The cellulose nanofibers, however, are sub-grouped into: (1) cellulose nanofibrils with a variety of terminologies that have been employed including mainly nanofibrillar cellulose, nanofibrilated cellulose, nanoscale-fibrillated cellulose, cellulosic fibrillar fines, nanofibers,

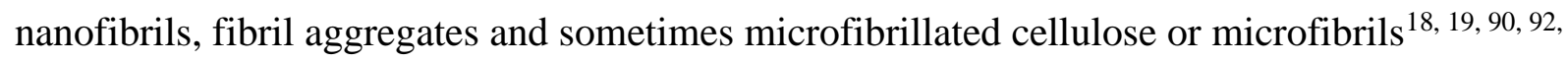
93; and (2) cellulose nanocrystals with different names that have been received throughout the 
years including cellulose whiskers, cellulose nanowhiskers, cellulose crystallites, nanorods, nanocrystalline cellulose, rodlike cellulose crystals, and nanowires ${ }^{3,21,35,90}$. The nomenclature that will be used further (cellulose nanocrystals) in the present paper is in agreement with the TAPPI standard recommendation.

\section{Cellulose nanocrystals}

Cellulose fibrils have several highly crystalline regions owing to the linear and conformationally homogeneous nature of the cellulose polymer and the extensive intermolecular hydrogen bonding between adjacent cellulose chains. The degree of crystallinity and size of the crystalline regions depend on the natural source of the cellulose and the isolation process. For instance, the degree of crystallinity may vary from approximately $50 \%$ in many plants to $60 \%$ in bacterial cellulose, $80 \%$ in tunicates and up to $90 \%$ in some algae ${ }^{94}$. Regarding the isolation of crystalline cellulosic domains in the form of CNCs, a facile process primarily focused on acid hydrolysis is generally employed. The idea of employing acid hydrolysis process to isolate $\mathrm{CNCs}$, from the disordered intercrystalline regions of the networks of cellulose chains, was initiated by Nickerson and Habrle ${ }^{95}$ and confirmed by Rånby ${ }^{96}$, when he produced colloidal suspensions of cellulose crystals. Later, Marchessault ${ }^{97}$ and coworkers in 1959 and Hermans ${ }^{98}$ in 1963 showed that birefringent liquid crystalline phases could be obtained and revealed that such colloidal suspensions of CNCs exhibit the nematic liquid crystalline order. However, interest in CNCs only began to grow after the publication of studies by Revol and coworkers ${ }^{99}$ in 1992, who demonstrated that a stable chiral nematic (cholesteric) liquid crystalline phase is formed in aqueous suspensions of CNCs above a critical concentration, and by Favier et al. in 1995 on CNCs as composite reinforcement ${ }^{100}$.

CNCs consist of "rod-like" or "needle-like" particles with high crystallinity and high specific surface area that can be derived from different natural sources. Fig. 4 represents the 
transmission electron micrographs (TEM) of selected cellulose nanocrystals. The dimensions and the crystallinity of these nanocrystals depend on the origin of the cellulose fibers as well as the procedure employed to obtain them. Conventionally, highly crystalline CNCs with spherical or shorter rod-shaped morphologies were typically produced from terrestrial woody biomass using acid hydrolysis (aspect ratios between 10 and 30). However, higher aspect ratios of $\mathrm{CNCs}$ with a length of several micrometers were commonly derived from bacteria and tunicates (aspect ratio around 70) ${ }^{101}$. The size of CNCs can vary from $100 \mathrm{~nm}$ to several micrometers in length and 4 to $70 \mathrm{~nm}$ in width ${ }^{75,102}$. During the synthetic process, cellulose chains primarily combined in fascicular microfibrils. The amorphous domains distributed as chain dislocations on segments along the elementary fibril are more available to acid and more disposed to hydrolytic action due to kinetic factors and reduced steric hindrance; whereas crystalline domains present a higher resistance to acid attack ${ }^{20,94,103}$. Thus, CNCs can be afterward produced on the removal of the amorphous regions from microfibrils at the defects.

Pristine cellulose has been found to have limited reactivity due to its functionalities; however the three-dimensional hierarchical structures composed of cellulose nanocrystals open up new opportunities for new fields, ranging from engineering to biomedical. CNCs impart attractive combinations of physicochemical characteristics ${ }^{20}, 30,33,43,67$, such as biocompatibility, biodegradability, optical transparency and anisotropy, low cost, high tensile strength, elasticity, low density, large specific surface area, and adaptable surface chemistry. Such unique CNCs' properties have promoted the progress of a wide range of new functional biomaterials, transforming research in different academic disciplines of science and engineering's. At laboratory scale, CNCs have been widely used as sustainable low-cost environmental friendly materials in miscellaneous fields $25,33,43,103-105$ including composites, separation membranes, barrier films, specific enzyme immobilization, supercapacitors, 
antimicrobial films, medical implants, green catalysts, emulsion stabilizers, biosensors, drug delivery, batteries, and templates for electronic devices. However, in spite of the huge potential of CNCs, for real life applications, the processing has some limitations. These limitations must have to be overcome in order to effectively utilize these CNCs at large scale $^{35,104}$.

\subsection{Cellulose nanocrystals sources}

Sustainable materials from renewable resources have attracted immense research interest during the last two decades owing to their potential for producing several high-values products with environmental friendly advantages. Different types of sources such as plant cell walls, cotton, microcrystalline cellulose, algae, animals and bacteria can be used to derive CNCs. Several CNCs with variable structure, properties and applications could be obtained, depending on the source, maturity, origin, processing methods and reaction parameters. A detailed study on research employing different source materials for extraction of cellulose particles has been beautifully compiled by Dufresne ${ }^{20}$ in his book and review by Agbor ${ }^{106}$. In the following subsections, a concise overview of cellulose nanocrystals sources will be presented.

\subsubsection{Lignocellulosic sources}

Lignocellulosic fibers (woody and non-woody plants) are considered as excellent feedstock for production of various materials that has been proven by the high number of patents and

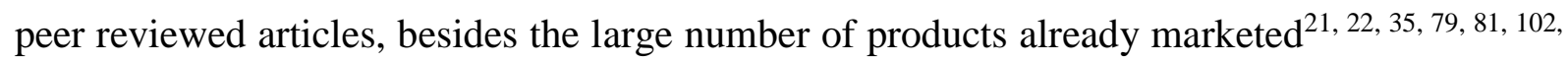
${ }^{106-110}$. Lignocellulosic natural fibers can be generally classified based upon the origin of the plant: (1) bast or stem, (2) leaf, (3) seed or fruit, (4) grass, and (5) straw fibers ${ }^{65}$. All over the world, more than 2000 species of useful fiber plants have been reported ${ }^{79}$. Woody and nonwoody plants can be refereed as cellular hierarchical bio-composites created by nature in which hemicellulose/lignin, waxes/ extractive and trace element serves as matrix materials 
while semicrystalline cellulose microfibril act as reinforcement ${ }^{33,81}$. A number of factors such as chemical composition and internal fiber structure significantly affect the properties of natural fibers along with the change between various parts of a plant and among different plants. An effective removal process of hemicellulose, lignin and other impurities gives rise to pure cellulose. CNC is currently manufactured from various lignocellulosic sources using topdown technologies. Wood is apparently the main source of cellulosic fibers, and is consequently the most important raw material used in the production of $\mathrm{CNCs}^{11,76,111}$. Nevertheless, competition among numerous areas such as furniture, pulp and paper industries, building products along with the combustion of wood for energy, renders it challenging to offer all sectors with the necessary quantities of wood at a reasonable price. Moreover, wood is not available in several regions, thus tuning its options to non-woody cellulose ${ }^{15}$. Hence, interest in other sources such as herbaceous plants, grass, aquatic plants, agricultural crops and their by-products has extensively stimulated significant interest. In their fibers, the cellulosic microfibrils are less tightly wound in the primary cell wall than in the secondary wall in wood, this fibrillation to made CNCs should be easiest ${ }^{16}$. These non-woody plants usually encompass less lignin as compared to the quantity found in wood. Therefore, bleaching methods are less chemical and energy demanding.

In recent years, wide variety of annual plants as well as agricultural residues have been investigated for the isolation of CNCs, including sesame husk ${ }^{110}, \operatorname{cotton}^{112-114}$, rice husk ${ }^{115}$, oil palm $^{27,116,117}$, Groundnut Shells ${ }^{118}$, macrophyte Typha domingensis ${ }^{87}$, potato peel ${ }^{119}$, jute ${ }^{120}$, spruce bark $^{121}$, agave angustifolia fibers ${ }^{122}$, mango seed ${ }^{123}$, sugarcane bagasse ${ }^{39,} 124,125$, corncob $^{126}$, bamboo ${ }^{127}$, straws ${ }^{30}$, soy hulls ${ }^{128}$, olive stones ${ }^{129}$, Miscanthus Giganteus ${ }^{28}$, $\operatorname{kapok}^{130}$, Flax Fibers ${ }^{131}$, pineapple leaf and $\operatorname{coir}^{130}$, banana ${ }^{130,132}$, sisal ${ }^{133}$, tomato peels ${ }^{134}$, calotropis procera fibers ${ }^{31}$, onion waste ${ }^{135}$, citrus waste ${ }^{136}$ and coconut ${ }^{137,138}$. Other recent explored sources for CNCs preparation have been reviewed in Table 2 as well. CNCs 
obtained from different types of cellulose sources of miscellaneous provenance using various isolation processes and conditions commonly differ in their degree of polymerization, morphology, surface charge, geometrical dimensions, crystallinity, surface area, porosity, mechanical properties, thermal stability, etc.

\subsubsection{Animal, algae and bacterial sources}

Although lignocellulosic materials are considered as the most common sources of cellulose, other living organisms including animals, bacteria and some types of algae can also be employed to produce cellulose microfibrils.

Tunicates, which live in the oceans, are revealed as the only animal source for cellulose. The name "Tunicata" has been derived from its unique integumentary tissue the "tunic", which covers the entire epidermis of the animal. In the tunic tissues, the cellulose microfibrils act as a skeletal structure. Cellulose-synthesizing enzyme complexes that exist in the plasma membrane of their epidermal cells are responsible for cellulose synthesis. Tunicates include three classes, and only two classes (Ascidiacea and Thaliacea) contain tunics. There are over 2300 species in Ascidiacea alone ${ }^{22}$. To extract and utilize the cellulose from tunicates, the quantity or production yield is crucial. Historically, the tunic has been reported to contain approximately $60 \%$ cellulose and $27 \%$ nitrogen-containing components by dry weight ${ }^{139}$. It was confirmed that the cellulose present in tunics is chemically identical with plant cellulose. However, tunicate cellulose shows different functions in various tunicates families and species, giving rise to difference in the structure. It was reported that more than 40 species of ascidian have been investigated for their structural diversity ${ }^{140}$. Typically, tunicate cellulose is composed of nearly pure cellulose I $\beta$. Hundreds of cellulose microfibrils are bundled in the tunic; the shape and dimensions of the microfibril bundle vary depending on the species. Noticeably, the Ciona intestinalis tunicate species could be farmed at very high densities in the ocean, allowing tunicate cellulose fabrication at a large scale ${ }^{141}$. Therefore, tunicates 
should be excellent candidate for CNCs preparation. The most frequently investigated species have been Ciona intestinalis ${ }^{41}$, Ascidia sp. ${ }^{139}$, Halocynthia roretzi ${ }^{142}$, Metandroxarpa uedai ${ }^{22}$, Styela plicata ${ }^{139}$ and Halocynthia papillosa ${ }^{143}$.

Although cellulose feedstock is generally associated with lignocellulosic materials, it is now well-known that cellulose microfibrils are also produced by algae (green, gray, red, yellow-green, etc. $)^{22}$. Many studies have demonstrated that red algae such as Gelidium, mainly composed of cellulose and agar, are a viable resource for numerous applications due to its high carbohydrate content ${ }^{144,145}$. In 2010, Seo and coworker have first described the use of two different species of red algae, namely Gelidium amansii and Gelidium corneum for the production of bleached pulp in papermaking industry ${ }^{146}$. Gelidium elegans was also utilized to produce cellulose nanomaterials ${ }^{40}$. The production of red algae has increasing exponentially from 5.3 million tons in 2006 to 10.8 million tons in $2011^{144}$. Therefore, the Gelidium red algae appear to be a new promising candidate for cellulose nanomaterials production than terrestrial biomass because of their abundance and availability. Besides, green algae are reported to be appropriate for cellulose extraction as well. Cellulose-producing algae belong generally to the orders Cladophorales (Cladophora, Chaetomorpha, Rhizoclonium, and Microdyction) and Siphonocladales (Valonia, Dictyosphaeria, Siphonocladus, and Boergesenia $)^{147}$. The cellulose obtained from Valonia or Cladophora presents a high degree of crystallinity, which can exceed $95 \%{ }^{77}$. Because of the biosynthesis process, cellulose microfibril structures have been found to be different for the different algae species.

The bacteria-derived cellulose is of prime concern owing to its high mechanical properties, good chemical stability, highly crystalline network structure, high chemical purity, an ultrafine and large water-holding capacity, light weight, renewability, biodegradability and non-toxicity which avoids chemical treatments employed in plant-derived celluloses for the elimination of lignin and hemicellulose ${ }^{21}$. Several excellent reviews and papers concerning 
the characterization and properties of bacterial cellulose (BC) and its possible applications have recently appeared ${ }^{20,80,148-150}$. As a result to its special properties, cellulose produced by bacteria has grown in popularity since its discovery in 1886. That strain was called Acetobacter xylinus, but there are other bacteria able to produce cellulose, such as Agrobacterium, seudomonas, Rhizobium and Sarcina ${ }^{148}$. The most efficient producers are gram-negative acetic acid bacteria Acetobacter xylinum (also called genus Gluconacetobcater) which has been reclassified and included within the novel Komagataeibacter as K. $x y$ linus $^{151}$. It has continued to be the highest producer of bacterial cellulose so far. It is stringently aerobic, non-photosynthetic and able to convert glucose and other organic substrates into cellulose in a few days ${ }^{149}$.

\subsection{Cellulose isolation methods}

Two main steps that are used to isolate CNCs from a raw cellulose sample include (i) homogenization pretreatment/ purification and (ii) the separation of the purified cellulose into its nanocrystals components. Thus, to prepare cellulose nanocrystals, cellulose can be directly hydrolyzed. Apart from pure cellulosic sources such as cotton, bleached wood pulp, and MCC, other cellulose sources are generally first submitted to different pretreatments. Detailed descriptions of several of these isolation methods are given below.

\subsubsection{Isolation of cellulose from lignocellulosic sources}

The amount of cellulose in various natural sources can vary depending on the species and life time of the plants. In nature, lignocellulosic is a bio-composite which results from a combination between nanoscale domains of cellulose, hemicellulose, lignin, extractives and contaminants. From technological point of view, lignin content evaluation is a crucial parameter to well optimize the pretreatment process needed to extract a pure cellulose pulp. Indeed, lignin is considered the hardest chemical component to be removed from lignocellulosic materials ${ }^{15}$. However, there are several procedures to isolate cellulose from 


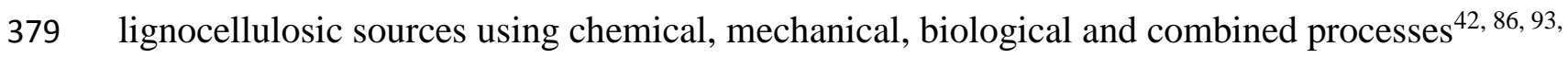

$380 \quad 106$. These processes have often been used as a pretreatment to simplify the hydrolysis process 381 for the production of CNCs. The pristine cellulose fibers are commonly boiled in toluene/ 382 ethanol (volume ration of 2:1) mixture after water-washing process to remove the dirt/ 383 impurities, water soluble extractives, wax and pectin, respectively. An example of cellulose 384 extraction procedure from tomato peels is shown in Fig. 5.

In chemical pulping process, some chemical agents are used to dissolve the lignin as well as hemicellulose (both surrounds the cellulose fibers). The most common methods for dissolving lignin and hemicellulose are either based on the Kraft process which uses sodium hydroxide $(\mathrm{NaOH})$ and sodium sulfide $\left(\mathrm{Na}_{2} \mathrm{~S}\right)$, followed by a bleaching step usually involving chlorine dioxide $\left(\mathrm{ClO}_{2}\right)$, hydrogen perixde $\left(\mathrm{H}_{2} \mathrm{O}_{2}\right)$, ozone $\left(\mathrm{O}_{3}\right)$, or peracteic acid. Many chlorine and/or sulfide-free treatments have been developed in order to decrease the environment impact of the pulping process. The preliminary steps to obtain pure cellulose fibers are crucial and must be performed carefully. The kraft extraction is done to solubilize most of the lignin and hemicelluloses and the bleaching treatment is made to break down phenolic compounds /molecules with chromophoric groups (in lignin) and to eliminate the byproducts of such breakdown, to whiten the material. However there are some serious environmental concerns related to the chemical pulping especially the by-products and residues of the process.

Mechanical methods are energy consuming, generally demanding high levels of pressure or kinetic energy. The product, derived from the mechanical pulping, presents commonly 400 similar composition than that of the original feeding. A number of mechanical processes have been frequently employed for the extraction cellulose fibrils from a wide range of cellulose sources. Some of the most mechanical methods include comminution, high pressure homogenization, microfluidization, cryocrushing, high intensity ultrasonication. 
Along with the commonly used traditional pulping processes, biological or enzymatic pulping has received much attention. This method depends on the ability of certain microorganisms and their secreted enzymes (i.e., xylanase) to directly attack hemicellulose and change the interface among lignin and cellulose, subsequently easing the removal of the lignin-associated hemicellulose fraction. This process indeed simplifies the extraction of purified cellulose with less degradation and superior quality pulps.

Combinatorial pretreatment strategies are usually more effective in increasing the biomass digestibility and improving the cellulose isolation, and often used in designing leading pretreatment technologies. The well-known physicochemical process involves is the combination of a mechanical method to decrease the reaction times by enhancing chemical accessibility. The tight intertwined fiber architecture is loosened by mechanical interactions, and the region exposed to the chemical action is enlarged ${ }^{152,153}$.

\subsubsection{Isolation of cellulose from animal, algae and bacterial sources}

Tunicates are marine invertebrate sea animals that have been recently known for producing cellulose in large amounts. The common process used for the extraction of cellulose is the prehydrolysis-kraft cooking-bleaching sequence, which is originated from Koo et $a l .{ }^{154}$. The isolation procedure from Halocynthia roretzi is depicted in Fig. 6. Similar method can applied for the cellulose isolation from other tunicates species $^{139}$. Basically, tunicate tunic can be obtained by eliminating the interior organs of the animal with a knife; the wet tunicate tunic will be then freeze-dried and milled into powders. A simple prehydrolysis procedure can be performed using an aqueous $\mathrm{H}_{2} \mathrm{SO}_{4}$ solution at $180{ }^{\circ} \mathrm{C}$ for $2 \mathrm{~h}$ with occasionally shaking in order to remove all lipids, ash and other sugars than glucose. The derived insoluble residue was recovered by filtration, washed thoroughly with acetone/water and freeze dried. A kraft cooking step can be subsequently conducted using an aqueous solution of $\mathrm{NaOH} / \mathrm{Na}_{2} \mathrm{~S}$ at 180 ${ }^{\circ} \mathrm{C}$ for $2 \mathrm{~h}$ with occasionally shaking to eliminate proteins and some residual sugars other than 
glucose, followed by filtration, washing and drying. Finally, a bleaching process can be performed using aqueous $\mathrm{NaClO}$ solution with agitation at $75{ }^{\circ} \mathrm{C}$ for $1 \mathrm{~h}$ to remove the residual proteins and some chromophoric structures initially present in the tunics or generated from the previous steps. This process can be repeated several times until the product becomes completely white. This sequence is considered to be a more suitable method than those mentioned in the literature ${ }^{155-157}$, since the original dissolving pulp process has proven very effective and specific for cellulose preservation, resulting in limited damage to cellulose, particularly crystalline cellulose ${ }^{139}$.

To prepare high quality cellulose pulp from algae more efficiently, non-cellulosic components need to be eliminated from the algae during the isolation process. Some researchers have reported that the biomass should be washed with distilled water in so as to ensure the removal of dirt/ contaminations on the fibers' surface ${ }^{40}$. Subsequently, the fibers are dried and these dried fibers are then grounded into powder form. A standard dewaxing process is then applied in a soxhlet apparatus system by using toluene/ethanol, followed by an alkalization treatment with $\mathrm{NaOH}$ to solubilize the agar (mucilaginous materials) from the marine algae plant at $80{ }^{\circ} \mathrm{C}$ for $2 \mathrm{~h}$. An efficient bleaching procedure is crucial to eliminate the natural pigment and chlorophyll to produce a highly purified, whiteness isolated cellulose pulp form the algae biomass. Two main oxidizing bleaching agents namely sodium chlorite $\left(\mathrm{NaClO}_{2}\right)$ and hydrogen peroxide $\left(\mathrm{H}_{2} \mathrm{O}_{2}\right)$ are commonly employed to bleach the algae biomass fiber to obtain bleached algae pulp ${ }^{40,158-160}$.

450 bacteria $^{20}$. For instance, K. xylinus can produce cellulose microfibrils in the form of flat, clear, and thick pellicles that floats on the surface of the growth medium. The obtained cellulose pellicles contain pure cellulose as well as a large proportion of water and some other ingredients of the medium. Dilute alkaline solution are capable of hydrolyzing and removing 
the impurities which exist in the cellulose pellicle. The washed cellulose pellicles can also be dried and cellulose membranes can be then easily processed from these pellicles ${ }^{77}$. Furthermore, BC is commonly considered as a highly hydrated and pure cellulose membrane and hence no chemical actions are required to eliminate hemicelluloses and lignin, as is the case for lignocellulosics ${ }^{16}$. A number of studies have resulted in the development of BC on an industrial scale, with a continuous/ semi-continuous process, economic raw materials and small production of by-products ${ }^{102,149}$. Some detailed studies concerning the mechanism of BC production using the fermentation process have been previously elaborated ${ }^{148,149}$.

\section{Extraction processes of cellulose nanocrystals}

Some significant research programs have been recently started on the production of cellulose nanocrystals at the industrial scale. As far as we know, four commercial entities producing CNCs at capacities beyond pilot plant scale: CelluForce (Canada, $1000 \mathrm{~kg} / \mathrm{day}$ ), American Process (U.S., 500 kg/day), Melodea (Israel, 100 kg/day), Melodea/Holmen (Sweden, $100 \mathrm{~kg} /$ day) and Alberta Innovates (Canada, $20 \mathrm{~kg} /$ day) $)^{35,161}$. Furthermore, various research facilities are currently producing CNCs, and several new lab and pilot scale have been announced such as US Forest Products Lab (U.S., 10 kg/day), Blue Goose Biorefineries (Canada, $10 \mathrm{~kg} /$ day), India Council for Agricultural Research (India, $10 \mathrm{~kg} /$ day) and FPInnovation (Canada, $3 \mathrm{~kg} / \mathrm{day})^{161}$.

It is well known that the morphology, physicochemical properties and mechanical characteristics of CNCs exhibit variations according to the origin of the raw material and the extraction process. The latter step is crucial for further processing and developing CNCs into functional, high-value added products, and, as such, efforts to face the shortcomings in the conventional methodology, to increase the production with a reduced cost are continuously reported in the literature. As shown above, CNCs can be extracted from various raw materials on earth that firstly need to follow a pretreatment procedure for complete/ partial removal of 
the matrix materials (e.g. lignin/ hemicelluloses/ fats/ waxes/ proteins, etc.) resulting in the extraction of the individual cellulose fibers. Depending on the source of the cellulose, the naturally occurring bulk cellulose primarily consists of highly ordered crystalline domains and some disordered (amorphous) regions in varying proportions ${ }^{77}$. When these microfibrils are subjected to a proper combination of chemical, mechanical, oxidation and/or enzymatic treatments, the crystalline domains of the cellulose microfibrils can be isolated, giving rise to the formation of cellulose nanocrystals. The production of CNCs in an economic and sustainable way and further exploration of its functional products are currently the major tasks for the researchers both from the academia and industry. Several methods are reported for isolation of CNCs (Table 3), namely, chemical acid hydrolysis, enzymatic hydrolysis, mechanical refining, ionic liquid treatment, subcritical water hydrolysis, oxidation method and combined processes.

\subsection{Acid hydrolysis}

In this method, a given concentration of desired acid and deionized water is mixed with the purified starting material. This process is the most commonly used technique for the separation of $\mathrm{CNCs}$ from cellulose fibers ${ }^{11}, 20,22,23,102$. The procedure involves an acidinduced destructuring process, during the course of which the heterogeneous acid hydrolysis involves the diffusion of acid molecules into cellulose microfibrils. It results in the cleavage of glycosidic bonds within cellulose molecular chains in the amorphous domains along the cellulose fibrils, thus leading to the breaking of the hierarchical structure of the fibril bundles into $\mathrm{CNCs}^{3,33}$. The difference in the kinetics of hydrolysis between paracrystalline and crystalline regions led to the selective cleavage of cellulosic chains ${ }^{20}$. The mostly common chemical function of the employed acids is their ability to release hydronium ions that tend to penetrate the cellulosic material in the amorphous domains and react with the oxygen elements on the glycosidic bonds between two anhydroglucose moieties to initiate protonation 
of oxygen elements, and hence hydrolytic cleavage of glycosidic bonds of amorphous regions ${ }^{15,33}$. The acidic treatment could hydrolyze the residual pectin and hemicellulose by breaking down the polysaccharides into simple sugar as well. The literature mentioned that these crystallites can grow in size owing to the large freedom of motion after hydrolytic cleavage, and consequently the crystallites will be larger in dimension than the original microfibrils ${ }^{20}$. Acid hydrolysis results in a rapid decrease in the degree of polymerization of cellulose nanocrystals. At the end of the process, the mixture undergoes a series of separation and washing/rinsing steps that is followed by dialysis against deionized water to eliminate residual acid and neutralized salts (Fig.7). To get the better and homogeneous dispersion of CNCs in aqueous media, sonication treatment is generally applied $8,11,22,26,102,158$. A schematic presentation of the acid hydrolysis process is shown in Fig. 7c.

Various acids such as sulfuric acid, hydrobromic acid, hydrochloric acid, phosphoric acid, maleic acid, and hydrogen peroxide have been assayed to extract CNCs from different resources. However, sulfuric and hydrochloric acids are frequently employed for the acid hydrolysis of corresponding cellulose $\mathrm{e}^{8,20,42,102}$. Numerous researchers had analyzed the effect of processing conditions on the physicochemical, thermal and mechanical properties. The temperature and time of hydrolysis procedure, nature and concentration of acid as well as the fiber-to acid ratio play an important role in the particle size, morphology, crystallinity, thermal stability and mechanical properties of $\mathrm{CNCs}^{20,162-165}$. Increment in the hydrolysis time has been reported to reduce the length of the nanocrystals as well as increase the acid/fiber ratio and reduce the crystals dimensions ${ }^{102,166}$.

The selection of an acid affects the properties of the resulting cellulose nanocrystals. Those isolated using hydrochloric acid present low-density surface charges with limited dispersibility and tend to promote flocculation in aqueous suspensions ${ }^{11,26}$. This issue can be solved by surface functionalization. In contrasts, when sulfuric acid is employed, a highly 
stable colloidal suspension is produced owing to the high negative surface charge promoted by sulfonation of CNCs surface $22,33,84,90$. However, one disadvantage of this method is that sulfate groups catalyze and initiate the degradation of cellulose, particularly at high temperatures. Hence the CNCs have been found to have limited thermal stability, which certainly restricts the processing of $\mathrm{CNCs}$ based nanocomposites at high temperature ${ }^{46}$. Several other approaches have been suggested to address the thermal stability problem ${ }^{113}, 167$, ${ }^{168}$. For instance, the use of mixtures of hydrochloric acid and sulfuric acid generated CNCs with high thermal stability, unfortunately at the expense of lower dispersibility. Recently, highly thermally stable CNCs have been prepared via mild acid hydrolysis (phosphoric acid) and hydrothermal treatment (hydrochloric acid) ${ }^{46,53}$. However, these procedures are severely restricted by low yields and poor scalability because of the high consumption of solvents and time, respectively.

Although the previous acid-hydrolysis procedures are simple, some drawbacks are needed to be addressed. Some of such drawbacks include serious large water usage, equipment corrosion, and generation of huge amount of waste. Also, the prolonged exposure of cellulosic materials to harsh conditions (mineral acids) can decrease crystallinity as the crystalline regions are potentially subjected to hydrolysis and structure structural change ${ }^{169}$. In 2011, Tang et al. have investigated the substitution of strong liquid acids by solid acids for environmental and sustainable reasons ${ }^{47}$. Their work reported the use of a cation exchange resin hydrolysis method to produce CNCs with a yield of $50 \%$ and high crystallinity of $84 \%$. The authors have demonstrated that cation exchange resin catalyst is easiest to handle than liquid acids. Also it does not present hazards to personnel or causes severe equipment corrosion and can also be easily separated from the reaction products, can be regenerated and causes less waste. In another work, Liu et al. have demonstrated that phosphotungstic acid can be a potential candidate to produce CNCs through controlling hydrolysis parameters ${ }^{170}$. This 
green and sustainable method leads to prepare CNCs with relatively good dispersibility in aqueous phase and high thermal stability. The method of producing CNCs from bleached eucalyptus kraft pulp via $\mathrm{FeCl}_{3}$-catalyzed formic acid hydrolysis was developed by $\mathrm{Du}$ et $a l .{ }^{38}$. They proved that the obtained CNCs present high crystallinity and excellent thermal stability with a high yield of $70-80 \%$.

More recently, attention has turned towards other methodologies to produce CNCs based on acid hydrolysis principle. Yu et al. reported the preparation of CNCs with carboxylic groups from microcrystalline cellulose using single-step extraction based on citric/hydrochloric acid hydrolysis ${ }^{29}$. A schematic route for fabricating carboxylated CNCs is shown in Fig. 8. The authors mentioned that the optimal CNCs samples with increased crystallinity, best suspension stability and better thermal stability were achieved at the hydrolysis time of 4 hours. Kontturi et al. described the preparation of cellulose nanocrystals in high yields with minimal water consumption using hydrogen chloride $(\mathrm{HCl})$ vapor $^{45}$. They demonstrated that the use of $\mathrm{HCl}$ vapor gives rise to a rapid hydrolysis of cotton-based cellulose fibers. An increase in crystallinity was deduced without any mass loss in the cellulose substrate during hydrolysis and a minimal impact on the morphology of the cellulose substrate was seen. The degree of polymerization was quickly reduced to the leveling off degree of polymerization (LODP) of around 170, which corresponds to the LODP determined by the conventional method with liquid-phase $\mathrm{HCl}$ as well as literature values ${ }^{83}$. The yield achieved by the authors was $97.4 \%$ instead of $20-50 \%$ with a liquid/solid system ${ }^{171}$. The authors indicated that only the yield of $11 \%$ was reached when liquid $\mathrm{HCl}$ was employed. Another approach was also developed by Chen et al. to produce high thermal-stable functional CNCs using recyclable organic acid (oxalic, maleic, and p-toluenesulfonic acids $)^{172}$. They produced CNCs from a bleached eucalyptus kraft pulp exhibited good dispersion, high crystallinity index and better thermal stability with a higher yield. They 
revealed that the solid organic acids used can be easily recovered after hydrolysis reactions through crystallization at a lower or ambient temperature, due to their low water solubility.

\subsection{Mechanical treatment}

Mechanical methods have also been widely investigated for the production of nanoscale cellulose particles, either as part of the fabricating process employing combinations of acid hydrolytic, oxidative, and enzymatic treatment, or directly ${ }^{42,52,173}$. They include microfluidization, ultrasonication, high pressure homogenization or ball milling. These procedures are commonly employed to produce cellulose nanofibers which are characterized with a diameter in nanometers or tens of nanometers and a length of up to several microns ${ }^{21}$, 22. More recently, Amine et al. have developed a scalable mechanical method using a high energy bead milling (HEBM $)^{52}$. The authors isolated CNCs from and aqueous dispersion or dilute acid (phosphoric acid) dispersion of commercially available microcrystalline cellulose (MCC) micronized through a HEBM process. They revealed that the morphology and the aspect ratio values were quite similar to that of the CNCs prepared via acid hydrolysis. The production yields of CNCs ranged between $57-76 \%$. The resulted rod-like CNCs present a crystallinity index of $85-95 \%$ with high thermal stability suitable to withstand the melt processing temperature of most common thermoplastics. Another mechanical method also reported the isolation of CNCs via ultrasonication ${ }^{52,54}$. Rod shaped CNCs were produced from an aqueous dispersion of MCC using a purely physical method of high-intensity ultrasonication. The CNC presented diameters between 10 and $20 \mathrm{~nm}$ and lengths between 50 and $250 \mathrm{~nm}$. However, the production yield of CNC using this method does not exceed $10 \%$. The ultrasonication effect was found to be non-selective, meaning that it can eliminate both the amorphous and crystalline cellulose.

\subsection{Oxidation method}


In 2006, Saito et al. reported a new method to introduce charged carboxylate groups into cellulosic materials which helped disintegration into nanofibrils with smaller widths, by utilizing a much lower energy input in comparison to that of the traditional pure mechanical treatment ${ }^{174}$. This process involves oxidation of never-dried native celluloses mediated by the 2,2,6,6-tetramethylpiperidine-1-oxyl (TEMPO) radical and subsequent homogenization by the mechanical treatment. The mechanism of the TEMPO-mediated oxidation of cellulose, which is a one of the regioselective chemical modifications of primary hydroxyl groups, is well explained elsewhere ${ }^{90}$. The reaction occurs on the surface of cellulose fibers and in amorphous domains. As the carboxyl content is increased to a certain amount, cellulose starts to disperse in aqueous solution but the crystalline regions remain intact and can therefore be released $^{20}$. Surface carboxylated NCC has been prepared by oxidation. A direct ultrasonicassisted TEMPO-NaBr-NaClO system was employed to produce carboxylic cellulose nanocrystals from cotton linter pulp ${ }^{175}$. Some of the amorphous domains of the cellulose were found to be gradually hydrolyzed during the oxidation process, and a stable and well dispersed aqueous suspension was subsequently obtained in one step. Microscopic observations revealed the presence of cellulose nanocrystals 5-10 nm in width and 200-400 $\mathrm{nm}$ in length. Cao et al. have extracted cellulose nanocrystals using TEMPO-NaBr-NaClO system $^{62}$. They reported that a stable and transparent dispersion of CNCs ( $80 \%$ yield) was obtained with high crystallinity and high surface area. CNCs produced by TEMPO oxidation were able to be completely dispersed at the individual nanofibril level in water by electrostatic repulsion and/or osmotic effects. This behavior was attributed to the anionically charged sodium carboxylate groups that were densely present on the fiber surfaces ${ }^{176}$. However, TEMPO-mediated oxidation method still exhibits some serious drawbacks, such as toxic TEMPO reagents (leading to environmental issues), oxidation time, and limited oxidation at C6 primary hydroxyl groups in CNCs. Another oxidation method using periodate-chlorite was 
developed $^{60,177}$. Generally, periodate is firstly utilized to oxidize the C2 and C3 hydroxyl groups using chrolite. However, this two-step oxidation method requires the expensive and toxic periodate along with the disintegration process having very high energy consumption ${ }^{63}$. Moreover, the glycosidic rings will be successively split after the oxidation reaction, which may reduce molecular chain lengths/rigidity of the CNCs. Very recently, carboxylated CNCs presenting a similar mean particle length along with length polydispersity with yields in the range of $14-81 \%$ were successfully isolated from numerous cellulosic sources by one-step ammonium persulfate hydrolysis, but this method necessitates time-consuming alkaline pretreatments and long reaction times of $16-24 \mathrm{~h}^{61,63}$.

\subsection{Enzymatic hydrolysis}

The concentrated acid employed in the common acid hydrolysis procedures is hazardous, toxic, and corrosive; hence highly corrosion-resistant reactor and extreme precaution in material handling are needed in the process. This makes acid treatment an expensive route. Furthermore, the concentrated acid should be recovered after treatment to make the method economically and environmentally feasible. As compared with acid hydrolysis method, enzymatic fabricating of $\mathrm{CNCs}$ is a less expensive alternative preparation technique that removes the need for harsh chemicals and necessitates much less energy for mechanical fibrillation and heating ${ }^{48}$. Furthermore, enzymes that selectively degrade the amorphous domains of cellulose fibers, and do not considerably digest the crystalline areas, result in CNCs that preserve a hydroxyl group surface chemistry which allows for easier chemical manipulation, and thus an expanded commercial potential. Cellulases (mixtures of endoglucanases, exoglucanases, and cellobiohydrolases) are one such interesting class of enzymes having ability to act as a catalyst for the hydrolysis of the cellulose. These enzymes act synergistically in the hydrolysis of cellulose. Endoglucanase randomly attacks and hydrolyzes the amorphous domains while exoglucanase reacts with the cellulosic chain from 
653

654

either the reducing or nonreducing ends. Cellobiohydrolases hydrolyze cellulose from either the $\mathrm{C}_{1}$ or the $\mathrm{C}_{4}$ ends employing a protein in each case, into cellobiose sub-units ${ }^{20}$. Consequently, the cellulose not only gets into amorphous parts of cellulose fibers, but also affects the crystalline regions because of the function of Cellobiohydrolases (CBH). Nevertheless, the cellubiose that can be formed in the reaction process can absorb on the activity center of $\mathrm{CBH}$ and avoid the thorough enzymolysis. This favorable effect presents an advantage for the controlled enzymolysis production of $\mathrm{CNCs}^{50}$. Satyamurthy et al. have produced CNCs using a controlled microbial hydrolysis of MCC with the cellulolytic fungus Trichoderma reesei ${ }^{51}$. The production yield reported was $22 \%$. The authors concluded that the penetration of fungus into the crystalline domain of MCC during incubation resulted in reduced crystallinity of CNCs produced by microbial hydrolysis compared to that of acid hydrolysis. In order to overcome some of the problems caused by the use of enzymatic hydrolysis process, some authors utilized different pretreatments before enzymolysis to produce CNCs. Chen et al. pretreated natural cotton with DMSO, $\mathrm{NaOH}$ or ultrasonic waves and applied enzymatic treatment to prepare $\mathrm{CNCs}^{50}$. A highest yield of $32.4 \%$ was reached. Recently, $\mathrm{Xu}$ et al. employed a cloned endoglucanase derived from Aspergillus oryzae to hydrolyze pretreated hemp and flaw fibers ${ }^{49}$. They demonstrated that a pretreatment of fibers with sonication-microwave in $2 \% \mathrm{NaOH}$ solution leads to NCCs of better quality and higher yield. The methods of Xu et al. effectively eliminate the need for acids to fabricate CNCs, but the mechanical pretreatment is still costly, taking into account the processing required and the preprocessing performed before enzyme digestion. More recently, Anderson et al. examined the ability of enzymes with endoglucanase activity to produce $\mathrm{CNCs}^{48}$. They showed that cellulase from Aspergillus niger was capable of fabricating CNCs with minimal processing from feedstock of well-solubilized kraft pulp. The estimated yield in this case was $10 \%$. 

acceptable yields, advanced selectivity, and milder operating conditions in comparison to the

679

680

681

682

683

684

685

686

687

688

689

690

691

692

693

694

695

696

697

698

699

700

701 chemical processes. However, this technique is also still hindered by economical (i.e., high cost of cellulose enzyme) and technical (rate limiting step of cellulose degradation with a long processing period) constraints. The slow rate of enzymatic hydrolysis has been found to be affected by numerous factors that also comprise structural features resulting from pretreatment and enzyme mechanism ${ }^{178}$.

\subsection{Ionic liquid treatment}

Ionic liquids (ILs) have received increasing attention from the scientific community specifically as recyclable, highly stable, low melting point and low vapor pressure reagents, leading to innovative and sustainable solutions. They exhibit unique solvating properties and are considered as emerging environmentally friendly solvents for lignocellulosic materials pretreatment and processing. In spite of their unique advantages, their embodied energy and cost, the recyclability and the reuse of ILs undoubtedly appear to be indispensible for the conception of any environmentally and economically viable CNCs isolation process. Some research works attested that the recovery rate of ILs can be reached as high as $99.5 \%$ by evaporating the anti-solvents ${ }^{56}$. Currently, imidazolium-based acidic ILs, such as 1-butyl-3methylimidazolium chloride ([BMIM]Cl), 1-ethyl-3-methylimidazolium diethylphosphonate ([EMIM]DEP), 1-butyl-3-methylimidazolium acetate ([BMIM]OAc) and 1-butyl-3methylimidazolium hydrogen sulfate ([BMIM] $\left.\mathrm{HSO}_{4}\right)$, are considered as the most interesting and the most investigated solvents for cellulose. Moreover, numerous recent studies clearly demonstrated that ILs could be efficiently employed as alternative reaction media for selective and controlled cellulose hydrolysis leading to nanoscale particles isolation. Man et al. utilized $[\mathrm{BMIM}] \mathrm{HSO}_{4}$ to produce rod-like $\mathrm{CNCs}$ from $\mathrm{MCC}^{179}$. According to the authors, the hydrolysis mechanism with the $[\mathrm{BMIM}] \mathrm{HSO}_{4}$ would be quite similar to the acid 
hydrolysis with $\mathrm{H}_{2} \mathrm{SO}_{4}$. The potential of [BMIM] $\mathrm{HSO}_{4}$ was fruitfully emphasized, both dry and in aqueous medium, for isolation of rod-like CNCs from microcrystalline cellulose (yield of $48 \%$ ). A preferential dissolution of amorphous domains lead to the increase of crystallinity during the treatment, while the native conformation of cellulose type I was conserved ${ }^{180}$. Mao al. have developed a two-step hydrolysis approach (24-h swelling at ordinary temperature and 12-h hydrolysis at $100{ }^{\circ} \mathrm{C}$ ) employing $[\mathrm{BMIM}] \mathrm{HSO}_{4}{ }^{57}$. This procedure gives rise to good CNC surface properties (sulfur content as low as $0.2 \%$ ) with high production yields (up to 76\%). Another work of Tan et al. can be highlighted as well, where [BMIM]HSO 4 was

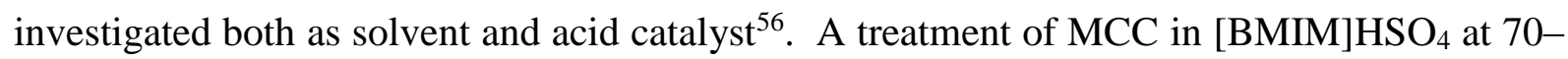
$100{ }^{\circ} \mathrm{C} 1 \mathrm{~h} 30$ was utilized to prepare rod-like cellulose nanocrystals. The authors mentioned that the basic cellulose I structure was preserved in CNCs during the catalytic conversion process and the degree of crystallinity of $95.8 \%$ was found to be higher compared to the MCC. Recently, Abushammala et al. have reported for the first time a direct extraction of CNCs from wood by means of [BMIM]OAc treatment ${ }^{58}$. They demonstrated that the obtained CNCs present high crystallinity of $75 \%$ and high aspect ratio of 65 with a yield of $44 \%$. They attributed the direct production of $\mathrm{CNCs}$ to the simultaneous capability of [BMIM] OAc to dissolve lignin in situ and at the same time resulting in the swelling of cellulose only. More recently, researchers have reported a facile one-pot preparation of hydrophobic CNCs from wood pulpboard using the solvent system tetrabutylammonium acetate/dimethylacetamide in conjunction with acetic acid, in which both the dissolution of amorphous cellulose and the acetylation of hydroxyl groups takes place ${ }^{181}$. A typical procedure has been shown in Fig. 9.The authors mentioned that the CNCs were found to be hydrophobic with a rod-like morphology, a good thermal stability and high crystallinity index. The yields of extraction were unfortunately not mentioned in this study. Lazko et $a l$. have reported the combination of ILs to produce $\mathrm{CNCs}^{55}$. They have extracted CNCs from cotton fibers using Brønsted acid- 
type ionic liquids (ILs) via a two-step swelling/hydrolysis route. Water addition was used as a medium to switch between these two stages. This complete process was accomplished in a single reaction medium predominantly based on [BMIM]Cl and 1-(4-sulfobutyl)-3-

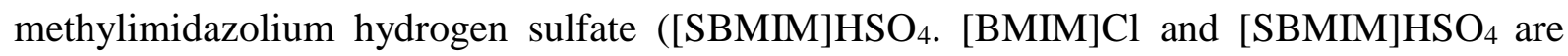
known for their capacity of dissolving cellulose in function of water and promoting hydrolytic processes, respectively ${ }^{55,182}$. Both swelling and hydrolysis of the cellulosic substrate were

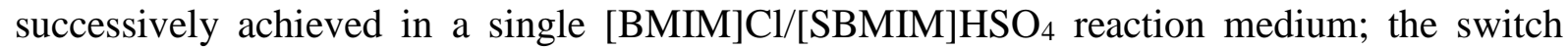
between the two swelling and hydrolysis steps being merely induced by water content variation.

\subsection{Subcritical water hydrolysis}

The aptitude of water to hydrolyze polysaccharides is well known, as seen in hydrothermal processes of hemicelluloses elimination ${ }^{183}$. The main characteristics for a prevalent hydrolysis rate are both the presence of water molecules and the availability of $\mathrm{H}_{3} \mathrm{O}^{+}$species and water. Sub- and supercritical water has lower values of $K_{w}$ and, therefore, higher concentrations of ionized species ${ }^{184}$. Consequently, their utilization could be efficient for the hydrolysis reactions. Some study has previously employed water at high temperature and pressure to hydrolyze lignocellulosic materials. Very few investigations have been reported concerning the production of CNCs by subcritical water hydrolysis method ${ }^{32,59}$. The exclusive utilization of water as reagent is a promising procedure not only for its green characteristics but for its low and cleaner effluent, low corrosion, and low cost of reagents as well ${ }^{59}$. Novo et al. produced CNCs from commercial microcrystalline cellulose using this process ${ }^{59}$. The authors reported that optimization of reaction conditions leads certainly to a good quality of CNCs with a higher yield ${ }^{32}$. They used subcritical water $\left(120^{\circ} \mathrm{C}\right.$ and $20.3 \mathrm{MPa}$ for 60 minutes $)$ to hydrolyze cellulose. The experimental conditions allow higher diffusion, activity and ionization of water. With that, partial hydrolysis of cellulose was reached with a yield of 
21.9\%. The obtained CNCs showed high crystallinity index $(79.0 \%)$, rod-like shape with similar aspect ratio as those reported for conventional cellulose nanocrystals. These CNCs in addition exhibited a higher thermal stability also in comparison with the original cellulosic source (onset around $300^{\circ} \mathrm{C}$ ).

\subsection{Combined processes}

There are several key factors such as CNC properties and yields that are affected by the source of cellulosic materials as well as different applied process ${ }^{103}$. Many efforts have been devoted to improve the properties and increase the yield in CNCs isolation, what play a crucial role in final application and cost. In this regards, the improvement of extraction technologies and development of combined processes using a combination of two or several of the aforementioned methods could be one of the most effective ways to enhance CNCs properties and address the yield restriction issue. Furthermore, numerous limitations still need to be considered, such as the pollution of the environment, the corrosion of equipment's and the difficulty in controlling the hydrolysis degree of cellulose ${ }^{35}$. A number of combined approaches for isolation of nanocrystals from cellulose have been reported. For instance, Tang et al. have examined the individualization of cellulose nanocrystals from commercial MCC employing a low-intensity sonication concept to improve the yield of CNCs based on sulfuric acid hydrolysis. The obtained results showed that the overall yield of CNCs was increased from $33 \%$ to $40 \%$ as a result of the supplement of sonication at $100 \mathrm{~W}$ for $30 \mathrm{~min}$ compared to the traditional sulfuric acid hydrolysis method ${ }^{185}$. Same research group has recently proposed a method of for isolating CNCs from old corrugated contained fibers employing a combined process that consists of enzymatic hydrolysis, phosphoric acid hydrolysis, and sonication. It was revealed that the obtained CNCs present high crystallinity, good thermal stability and improved dispersion with a higher yield of $28.98 \%$ with respect to CNCs derived from a single phosphoric acid hydrolysis process ${ }^{67}$. Another investigation by Beltramino et $a l$. 
allowed the optimization of the experimental condition to prepare CNCs using a combined process using acid hydrolysis assisted with enzymatic treatment ${ }^{66}$. Optimal conditions $(10 \mathrm{U} / \mathrm{g}$ odp cellulase, 25 min hydrolysis, $47{ }^{\circ} \mathrm{C}, 62$ wt. $\% \mathrm{H}_{2} \mathrm{SO}_{4}$ ) generated nanosized particles of around $\sim 200 \mathrm{~nm}$ with decreased surface charge and sulfur content. The optimization allowed reduction of hydrolysis time by $44 \%$ and increase of yield (>80\%). More recently, Rohaizu \& Wanrosli reported the use of sono-assisted TEMPO oxidation of oil palm lignocellulosic biomass to produce $\mathrm{CNCs}^{64}$. They demonstrated that the sono-assisted treatment has a remarkable effect, resulting in an increase of more than $100 \%$ in the carboxylate content and a significant increase of approximately $39 \%$ in yield compared with the non-assisted process. The obtained CNC displayed high crystallinity index of $72 \%$ and good thermal stability with a yield production of $93 \%$.

Ultrasonication wave and microwave techniques have also been used as assisting technologies in physicochemical treatments of plant fiber materials to attain high efficiency. Simultaneous ultrasonic wave microwave assisted method was first applied by Lu et al. to produce CNCs from filter paper using sulfuric acid hydrolysis. Under the optimal conditions, the yield and the crystallinity of CNCs with the crystal form of cellulose I $\alpha$ are $85.75 \%$ and $80 \%$, respectively ${ }^{68}$. Recently, Chowdhury \& Abd Hamid have reported the preparation of CNC from stalk of Corchorus olitorius employing the combination of ultrasonication and microwave $\mathrm{e}^{65}$. They pretreated the jute stalk powder with sodium hydroxide under microwave irradiation, followed by a bleaching with hydrogen peroxide. The obtained crude product was hydrolyzed by ultrasonication in the presence of various hydrolyzing mediums (ionic liquid or sulfuric acid). The derived rod-like CNCs exhibited high crystallinity index (>83\%). The yield percentage obtained using ionic liquid process (48\%) was higher than that obtained using sulfuric acid (43\%).

\subsection{Purification and fractionation $\mathrm{CNCs}$}


Since the common process used to produce CNCs is based on either pure acid hydrolysis or combined with another process, the resulting aqueous suspension is usually quenched by diluting with water at room temperature (eventually diluted with ace cubes) and in sometimes filtered over a small-pore fritted glass filter. This hydrolysis procedure, however, presents some post-treatment drawbacks, such as prolonged time and cost to eliminate free acid in the cellulose nanofibers, for their utilization in industrial scale. Part of the excess acid and watersoluble fragments can be removed during the centrifugations steps. The remaining free acid molecules from the dispersion can further be eliminated by dialysis against water until they achieve neutral $\mathrm{pH}$. This step is costly and takes long time (more than two or three days) as well $^{20,22}$. To address such issues, CNCs prepared from acid hydrolysis can be adjusted to $\mathrm{pH}$ about 9 using sodium hydroxide and washed with distilled water until to reach the neutrality ${ }^{186}$. Although this latter also took a long time, the chemical neutralization procedure remains simple with less processing steps to produce CNCs. Recently, it was demonstrated that $\mathrm{CNCs}$ neutralization method using $\mathrm{NaOH}$ was a simple, economic, and efficient with respect to the dialysis method ${ }^{187}$. The neutralization procedure can be followed by a disintegration of aggregates to generate a complete dispersion of the nanocrystals using a sonication step. The final aqueous suspension can be stored in a refrigerator after possible filtration to eliminate any residual aggregates and adding few drops of chloroform to avoid bacterial growth. The dialysis step in the acid hydrolysis extraction of CNCs procedure is not necessary when enzymatic, ionic liquid, subcritical water, oxidation and mechanical methods are employed. The main steps in this case consist of different treatments by washing, neutralization, centrifugation and sonication. Supplementary steps of post-treatment of the produced CNCs can be performed. For instance, the aqueous suspensions of CNC could be separated into isotropic and anisotropic phases by increasing the concentration (by water 
evaporation). Hirai et al. showed that the smaller nanoparticles lie in the isotropic phase whereas the longer ones are found in the anisotropic phase ${ }^{188}$.

To mitigate transportation costs during the processing of CNCs, drying of the final aqueous suspensions has been reported to be an imperative step. In most cases CNCs is treated as aqueous suspension because of its hydrophilic nature and tendency to agglomerate during drying $^{35}$. The well established procedures are supercritical drying, freeze drying, and spray drying $^{189}$. Results displayed that both the freeze and supercritical drying approaches generate highly networked structures of agglomerates having multi-scalar dimensions (e.g. nanoscale). Han et al. have reported on the self-assembling behavior of CNCs during freeze drying ${ }^{190}$. Fig. 10 depicts the formation mechanism of the lamellar geometry along with the alignment of ultrafine fibers during the freeze-drying process. On the other hand, the spray drying has been suggested as a technically suitable production procedure to dry CNCs suspensions ${ }^{189}$.

\section{Conclusions}

Environmental friendly bio-renewable materials form different natural resources has resulted in a great interesting in exploring new materials for advanced applications. Among different renewable materials, cellulose is the most important and common polymer available on the mother earth. Cellulose can be processed into different forms such as fibers; micro and nanocellulose. Very recently the cellulose nanocrystals (CNCs) are being explored for a number of advanced applications especially because of their crystalline structure and the properties resulting from the crystalline structure. However, in spite of the huge advantages of the cellulose nanocrystals, the energy consumption and production costs have limited their wide spread applications. Hence, the first part of this review article has focused on the different sources of cellulose and later has focused on the production methods for CNCs. In addition structural organization of cellulose and nomenclature of cellulose nanomaterials has also been discussed for beginners in this field. We believe that the studies presented in this 
851

852

853

854

855

856

857

858

859

860

861

862

863

864

865

866

867

868

869

870

871

872

873

874

875

876

877

878

879

880

881

882

883

884

885

article will increase the interest of researchers on cellulose based nanomaterials as well as the basic understanding of the cellulose nanocrystals.

\section{References}

1. Committee to Review the National Nanotechnology Initiative. A matter of size: Triennial review of the National Nanotechnology Initiative, National Academies Press, 2006.

2. Government \& Consortium Nanotechnology Programs, http://www.nanotechnow.com/government.htm, (accessed 26-12-2016, 2016).

3. M. Mariano, N. El Kissi and A. Dufresne, Journal of Polymer Science Part B: Polymer Physics, 2014, 52, 791-806.

4. M. C. Roco, C. A. Mirkin and M. C. Hersam, Journal of nanoparticle research, 2011, 13, 897-919.

5. R. Birringer, H. Gleiter, H.-P. Klein and P. Marquardt, Physics Letters A, 1984, 102, 365-369.

6. H. Tian and J. He, Langmuir, 2016.

7. V. K. Thakur, Lignocellulosic polymer composites: Processing, characterization, and properties, John Wiley \& Sons, 2015.

8. V. K. Thakur, Nanocellulose Polymer Nanocomposites: Fundamentals and Applications, John Wiley \& Sons, 2015.

9. A. Pappu, V. Patil, S. Jain, A. Mahindrakar, R. Haque and V. K. Thakur, Int. J. Biol. Macromol., 2015, 79, 449-458.

10. E. M. Fernandes, R. A. Pires, J. F. Mano and R. L. Reis, Prog. Polym. Sci., 2013, 38, 14151441.

11. D. Klemm, F. Kramer, S. Moritz, T. Lindström, M. Ankerfors, D. Gray and A. Dorris, Angew. Chem. Int. Edit., 2011, 50, 5438-5466.

12. S. Kalia, B. Kaith and I. Kaur, Cellulose fibers: bio-and nano-polymer composites: green chemistry and technology, Springer Science \& Business Media 2011.

13. D. Klemm, B. Heublein, H. P. Fink and A. Bohn, Angew. Chem. Int. Edit., 2005, 44, 33583393.

14. T. Abitbol, A. Rivkin, Y. Cao, Y. Nevo, E. Abraham, T. Ben-Shalom, S. Lapidot and O. Shoseyov, Current opinion in biotechnology, 2016, 39, 76-88.

15. D. Trache, M. H. Hussin, C. T. H. Chuin, S. Sabar, M. N. Fazita, O. F. Taiwo, T. Hassan and M. M. Haafiz, Int. J. Biol. Macromol., 2016, 93, 789-804.

16. I. Siró and D. Plackett, Cellulose, 2010, 17, 459-494.

17. V. K. Thakur and S. I. Voicu, Carbohyd. Polym., 2016, 146, 148-165.

18. F. Hoeng, A. Denneulin and J. Bras, Nanoscale, 2016.

19. N. Lin and A. Dufresne, European Polymer Journal, 2014, 59, 302-325. 
20. A. Dufresne, Nanocellulose: from nature to high performance tailored materials, Walter de Gruyter, 2013.

21. H. Charreau, M. L Foresti and A. Vázquez, Recent patents on nanotechnology, 2013, 7, 56-80.

22. R. J. Moon, A. Martini, J. Nairn, J. Simonsen and J. Youngblood, Chemical Society Reviews, 2011, 40, 3941-3994.

23. S. J. Eichhorn, Soft Matter, 2011, 7, 303-315.

24. G. Siqueira, J. Bras and A. Dufresne, Polymers, 2010, 2, 728-765.

25. Y. Habibi, L. A. Lucia and O. J. Rojas, Chem. Rev., 2010, 110, 3479-3500.

26. N. F. Vasconcelos, J. P. A. Feitosa, F. M. P. da Gama, J. P. S. Morais, F. K. Andrade, M. d. S. M. de Souza and M. de Freitas Rosa, Carbohyd. Polym., 2017, 155, 425-431.

27. J. Lamaming, R. Hashim, C. P. Leh and O. Sulaiman, Carbohyd. Polym., 2017, 156, 409-416.

28. E. Cudjoe, M. Hunsen, Z. Xue, A. E. Way, E. Barrios, R. A. Olson, M. J. Hore and S. J. Rowan, Carbohyd. Polym., 2017, 155, 230-241.

29. H.-Y. Yu, D.-Z. Zhang, F.-F. Lu and J. Yao, ACS Sustain. Chem. Eng., 2016, 4, 2632-2643.

30. A. A. Oun and J.-W. Rhim, Carbohyd. Polym., 2016, 150, 187-200.

31. A. A. Oun and J.-W. Rhim, Materials Letters, 2016, 168, 146-150.

32. L. P. Novo, J. Bras, A. García, N. Belgacem and A. A. da Silva Curvelo, Ind. Crop. Prod., 2016.

33. H.-M. Ng, L. T. Sin, T.-T. Tee, S.-T. Bee, D. Hui, C.-Y. Low and A. Rahmat, Composites Part B: Engineering, 2015, 75, 176-200.

34. R. M. Domingues, M. E. Gomes and R. L. Reis, Biomacromolecules, 2014, 15, 2327-2346.

35. L. Brinchi, F. Cotana, E. Fortunati and J. Kenny, Carbohyd. Polym., 2013, 94, 154-169.

36. B. Peng, N. Dhar, H. Liu and K. Tam, The Canadian Journal of Chemical Engineering, 2011, 89, 1191-1206.

37. M. H. Hussin, N. A. Pohan, Z. N. Garba, M. J. Kassim, A. A. Rahim, N. Brosse, M. Yemloul, M. N. Fazita and M. M. Haafiz, Int. J. Biol. Macromol., 2016, 92, 11-19.

38. H. Du, C. Liu, X. Mu, W. Gong, D. Lv, Y. Hong, C. Si and B. Li, Cellulose, 2016, 1-19.

39. F. B. de Oliveira, J. Bras, M. T. B. Pimenta, A. A. da Silva Curvelo and M. N. Belgacem, Ind. Crop. Prod., 2016, 93, 48-57.

40. Y. W. Chen, H. V. Lee, J. C. Juan and S.-M. Phang, Carbohyd. Polym., 2016, 151, 12101219.

41. Y. Zhao, Y. Zhang, M. E. Lindström and J. Li, Carbohyd. Polym., 2015, 117, 286-296.

42. J. Pandey, H. Takagi, A. Nakagaito and H. Kim, Handbook of polymer nanocomposites. Processing, performance and application, Springer, 2015.

43. J. P. Lagerwall, C. Schütz, M. Salajkova, J. Noh, J. H. Park, G. Scalia and L. Bergström, NPG Asia Materials, 2014, 6, e80.

44. N. Lin, J. Huang and A. Dufresne, Nanoscale, 2012, 4, 3274-3294. 
45. E. Kontturi, A. Meriluoto, P. A. Penttilä, N. Baccile, J. M. Malho, A. Potthast, T. Rosenau, J. Ruokolainen, R. Serimaa and J. Laine, Angew. Chem. Int. Edit., 2016, 55, 14455-14458.

46. S. Camarero Espinosa, T. Kuhnt, E. J. Foster and C. Weder, Biomacromolecules, 2013, 14, 1223-1230.

47. L.-r. Tang, B. Huang, W. Ou, X.-r. Chen and Y.-d. Chen, Bioresource Technol., 2011, 102, 10973-10977.

48. S. R. Anderson, D. Esposito, W. Gillette, J. Zhu, U. Baxa and S. E. Mcneil, TAPPI J, 2014, $13,35-41$.

49. Y. Xu, J. Salmi, E. Kloser, F. Perrin, S. Grosse, J. Denault and P. C. Lau, Ind. Crop. Prod., 2013, 51, 381-384.

50. X. Chen, X. Deng, W. Shen and L. Jiang, BioResources, 2012, 7, 4237-4248.

51. P. Satyamurthy, P. Jain, R. H. Balasubramanya and N. Vigneshwaran, Carbohyd. Polym., 2011, 83, 122-129.

52. K. N. M. Amin, P. K. Annamalai, I. C. Morrow and D. Martin, RSC Adv., 2015, 5, $57133-$ 57140.

53. H. Yu, Z. Qin, B. Liang, N. Liu, Z. Zhou and L. Chen, Journal of Materials Chemistry A, 2013, 1, 3938-3944.

54. W. Li, J. Yue and S. Liu, Ultrasonics Sonochemistry, 2012, 19, 479-485.

55. J. Lazko, T. Sénéchal, A. Bouchut, Y. Paint, L. Dangreau, A. Fradet, M. Tessier, J. M. Raquez and P. Dubois, Nanocomposites, 2016, 2, 65-75.

56. X. Y. Tan, S. B. A. Hamid and C. W. Lai, Biomass Bioenrg., 2015, 81, 584-591.

57. J. Mao, B. Heck, G. Reiter and M.-P. Laborie, Carbohyd. Polym., 2015, 117, 443-451.

58. H. Abushammala, I. Krossing and M.-P. Laborie, Carbohyd. Polym., 2015, 134, 609-616.

59. L. P. Novo, J. Bras, A. García, N. Belgacem and A. A. Curvelo, ACS Sustain. Chem. Eng., $2015,3,2839-2846$.

60. B. Sun, Q. Hou, Z. Liu and Y. Ni, Cellulose, 2015, 22, 1135-1146.

61. M. Cheng, Z. Qin, Y. Liu, Y. Qin, T. Li, L. Chen and M. Zhu, Journal of Materials Chemistry A, 2014, 2, 251-258.

62. X. Cao, B. Ding, J. Yu and S. S. Al-Deyab, Carbohyd. Polym., 2012, 90, 1075-1080.

63. A. C. Leung, S. Hrapovic, E. Lam, Y. Liu, K. B. Male, K. A. Mahmoud and J. H. Luong, Small, 2011, 7, 302-305.

64. R. Rohaizu and W. Wanrosli, Ultrasonics Sonochemistry, 2017, 34, 631-639.

65. Z. Z. Chowdhury and S. B. A. Hamid, BioResources, 2016, 11, 3397-3415.

66. F. Beltramino, M. B. Roncero, A. L. Torres, T. Vidal and C. Valls, Cellulose, 2016, 23, 17771789.

67. Y. Tang, X. Shen, J. Zhang, D. Guo, F. Kong and N. Zhang, Carbohyd. Polym., 2015, 125, 360-366. 
68. Z. Lu, L. Fan, H. Zheng, Q. Lu, Y. Liao and B. Huang, Bioresource Technol., 2013, 146, 8288 .

69. P. Huang, Y. Zhao, S. Kuga, M. Wu and Y. Huang, Nanoscale, 2016, 8, 3753-3759.

70. A. Boujemaoui, S. Mongkhontreerat, E. Malmström and A. Carlmark, Carbohyd. Polym., 2015, 115, 457-464.

71. F. Joubert, O. M. Musa, D. R. Hodgson and N. R. Cameron, Chemical Society Reviews, 2014, 43, 7217-7235.

72. M. Nagalakshmaiah, N. El Kissi and A. Dufresne, ACS applied materials \& interfaces, 2016, 8, 8755-8764.

73. X. Qin, W. Xia, R. Sinko and S. Keten, Nano letters, 2015, 15, 6738-6744.

74. R. J. Moon, G. T. Schueneman and J. Simonsen, JOM, 2016, 68, 2383-2394.

75. R. Singla, A. Guliani, A. Kumari and S. K. Yadav, in Nanoscale Materials in Targeted Drug Delivery, Theragnosis and Tissue Regeneration, Springer, 2016, pp. 103-125.

76. J.-H. Kim, B. S. Shim, H. S. Kim, Y.-J. Lee, S.-K. Min, D. Jang, Z. Abas and J. Kim, International Journal of Precision Engineering and Manufacturing-Green Technology, 2015, 2, 197-213.

77. J. George and S. Sabapathi, Nanotechnology, science and applications, 2015, 8, 45-54.

78. A. W. Carpenter, C.-F. de Lannoy and M. R. Wiesner, Environmental science \& technology, 2015, 49, 5277-5287.

79. C. J. Chirayil, L. Mathew and S. Thomas, Rev. Adv. Mater. Sci, 2014, 37, 20-28.

80. C. Miao and W. Y. Hamad, Cellulose, 2013, 20, 2221-2262.

81. A. Dufresne, Mater. Today, 2013, 16, 220-227.

82. J.-L. Wertz, J. P. Mercier and O. Bédué, Cellulose science and technology, CRC Press, Switzerland, 2010.

83. D. Klemm, B. Philipp, T. Heinze, U. Heinze and W. Wagenknecht, Journal, 1998.

84. S. Eyley and W. Thielemans, Nanoscale, 2014, 6, 7764-7779.

85. D. Trache, in Handbook of composites from renewable materials, eds. V. K. Thakur, M. Kumari Thakur and M. R. Kessler, Scrivener Publishing LLC, 2017, vol. 3, pp. 61-92.

86. N. Lavoine, I. Desloges, A. Dufresne and J. Bras, Carbohyd. Polym., 2012, 90, 735-764.

87. N. R. César, M. A. Pereira-da-Silva, V. R. Botaro and A. J. de Menezes, Cellulose, 2015, 22, 449-460.

88. International Organization for Standardization. ISO Technical Specification ISO/TS 27687, Nanotechnologies - Terminology and definitions for nano-objects-Nanoparticle, nanofiber and nanoplate).

89. International Organization for Standardization. ISO Technical Specification ISO/TS80004-1, Nanotechnologies - Vocabulary - Part 1: Core Terms). 
90. A. Vazquez, M. L. Foresti, J. I. Moran and V. P. Cyras, in Handbook of Polymer Nanocomposites. Processing, Performance and Application, Springer, 2015, pp. 81-118.

91. Standard Terms and Their Definition for Cellulose Nanomaterial. WI 3021, http://www.tappi.org/content/hide/draft3.pdf, (accessed 26-12-2016, 2016).

92. S. H. Osong, S. Norgren and P. Engstrand, Cellulose, 2016, 23, 93-123.

93. H. Abdul Khalil, Y. Davoudpour, M. N. Islam, A. Mustapha, K. Sudesh, R. Dungani and M. Jawaid, Carbohyd. Polym., 2014, 99, 649-665.

94. J. M. Dugan, J. E. Gough and S. J. Eichhorn, Nanomedicine, 2013, 8, 287-298.

95. R. F. Nickerson and J. A. Habrle, Ind. Eng. Chem., 1947, 39, 1507-1512.

96. B. G. Rånby, Acta. Chem. Scand., 1949, 3, 649-650.

97. R. Marchessault, F. Morehead and N. Walter, Nature, 1959, 184, 632 - 633.

98. J. Hermans, Journal of Polymer Science Part C: Polymer Symposia, 1963, 2, 129-144.

99. J.-F. Revol, H. Bradford, J. Giasson, R. Marchessault and D. Gray, Int. J. Biol. Macromol., 1992, 14, 170-172.

100. V. Favier, H. Chanzy and J. Cavaille, Macromolecules, 1995, 28, 6365-6367.

101. L. Valentini, M. Cardinali, E. Fortunati, L. Torre and J. M. Kenny, Materials Letters, 2013, 105, 4-7.

102. M. Jonoobi, R. Oladi, Y. Davoudpour, K. Oksman, A. Dufresne, Y. Hamzeh and R. Davoodi, Cellulose, 2015, 22, 935-969.

103. I. A. Sacui, R. C. Nieuwendaal, D. J. Burnett, S. J. Stranick, M. Jorfi, C. Weder, E. J. Foster, R. T. Olsson and J. W. Gilman, ACS applied materials \& interfaces, 2014, 6, 6127-6138.

104. W. Fang, S. Arola, J.-M. Malho, E. Kontturi, M. B. Linder and P. i. Laaksonen, Biomacromolecules, 2016, 17, 1458-1465.

105. D. Gaspar, S. Fernandes, A. De Oliveira, J. Fernandes, P. Grey, R. Pontes, L. Pereira, R. Martins, M. Godinho and E. Fortunato, Nanotechnology, 2014, 25, 094008.

106. V. B. Agbor, N. Cicek, R. Sparling, A. Berlin and D. B. Levin, Biotechnology advances, 2011, 29, 675-685.

107. D. Trache, K. Khimeche, A. Mezroua and M. Benziane, J. Therm. Anal. Calorim., 2016, 124, 1485-1496.

108. S. Ummartyotin and H. Manuspiya, Renew. Sust. Energ. Rev., 2015, 41, 402-412.

109. D. Trache, A. Donnot, K. Khimeche, R. Benelmir and N. Brosse, Carbohyd. Polym., 2014, 104, 223-230.

110. B. S. Purkait, D. Ray, S. Sengupta, T. Kar, A. Mohanty and M. Misra, Ind. Eng. Chem. Res., 2010, 50, 871-876.

111. A. Dufresne and M. N. Belgacem, Polímeros, 2013, 23, 277-286.

112. J. H. O. d. Nascimento, R. F. Luz, F. M. Galvão, J. D. D. Melo, F. R. Oliveira, R. Ladchumananandasivam and A. Zille, Materials today: proceedings, 2015, 2, 1-7. 
113. Y. Li, G. Li, Y. Zou, Q. Zhou and X. Lian, Cellulose, 2014, 21, 301-309.

114. J. P. S. Morais, M. de Freitas Rosa, L. D. Nascimento, D. M. do Nascimento and A. R. Cassales, Carbohyd. Polym., 2013, 91, 229-235.

115. S. M. Rosa, N. Rehman, M. I. G. de Miranda, S. M. Nachtigall and C. I. Bica, Carbohyd. Polym., 2012, 87, 1131-1138.

116. M. M. Haafiz, A. Hassan, Z. Zakaria and I. Inuwa, Carbohyd. Polym., 2014, 103, 119-125.

117. R. Dungani, A. F. Owolabi, C. K. Saurabh, H. A. Khalil, P. M. Tahir, C. Hazwan, K. A. Ajijolakewu, M. Masri, E. Rosamah and P. Aditiawati, J. Polym. Environ., 2016, DOI: 10.1007/s10924-016-0854-8, 1-9.

118. S. Bano and Y. S. Negi, Carbohyd. Polym., 2016, DOI: 10.1016/j.carbpol.2016.10.069.

119. D. Chen, D. Lawton, M. Thompson and Q. Liu, Carbohyd. Polym., 2012, 90, 709-716.

120. N. Kasyapi, V. Chaudhary and A. K. Bhowmick, Carbohyd. Polym., 2013, 92, 1116-1123.

121. M. Le Normand, R. Moriana and M. Ek, Carbohyd. Polym., 2014, 111, 979-987.

122. N. A. Rosli, I. Ahmad and I. Abdullah, BioResources, 2013, 8, 1893-1908.

123. M. A. Henrique, H. A. Silvério, W. P. F. Neto and D. Pasquini, Journal of environmental management, 2013, 121, 202-209.

124. A. Kumar, Y. S. Negi, V. Choudhary and N. K. Bhardwaj, Journal of Materials Physics and Chemistry, 2014, 2, 1-8.

125. E. de Morais Teixeira, T. J. Bondancia, K. B. R. Teodoro, A. C. Corrêa, J. M. Marconcini and L. H. C. Mattoso, Ind. Crop. Prod., 2011, 33, 63-66.

126. H. A. Silvério, W. P. F. Neto, N. O. Dantas and D. Pasquini, Ind. Crop. Prod., 2013, 44, $427-$ 436.

127. W. Chen, H. Yu, Y. Liu, Y. Hai, M. Zhang and P. Chen, Cellulose, 2011, 18, 433-442.

128. W. P. F. Neto, H. A. Silvério, N. O. Dantas and D. Pasquini, Ind. Crop. Prod., 2013, 42, 480488.

129. M. L. Hassan, R. E. Abou-Zeid, S. M. Fadel, M. El-Sakhawy and R. Khiari, International Journal of Nanoparticles, 2014, 7, 261-277.

130. B. Deepa, E. Abraham, N. Cordeiro, M. Mozetic, A. P. Mathew, K. Oksman, M. Faria, S. Thomas and L. A. Pothan, Cellulose, 2015, 22, 1075-1090.

131. A. Mtibe, Y. Mandlevu, L. Z. Linganiso and R. D. Anandjiwala, Journal of Biobased Materials and Bioenergy, 2015, 9, 309-317.

132. S. Mueller, C. Weder and E. J. Foster, RSC Adv., 2014, 4, 907-915.

133. M. Mariano, R. Cercená and V. Soldi, Ind. Crop. Prod., 2016, 94, 454-462.

134. F. Jiang and Y.-L. Hsieh, Carbohyd. Polym., 2015, 122, 60-68.

135. J.-W. Rhim, J. P. Reddy and X. Luo, Cellulose, 2015, 22, 407-420.

136. M. Mariño, L. Lopes da Silva, N. Durán and L. Tasic, Molecules, 2015, 20, 5908-5923. 
137. D. M. do Nascimento, A. F. Dias, C. P. de Araújo Junior, M. de Freitas Rosa, J. P. S. Morais and M. C. B. de Figueirêdo, Ind. Crop. Prod., 2016.

138. D. M. Nascimento, J. S. Almeida, A. F. Dias, M. C. B. Figueirêdo, J. P. S. Morais, J. P. Feitosa and M. d. F. Rosa, Carbohyd. Polym., 2014, 110, 456-463.

139. Y. Zhao and J. Li, Cellulose, 2014, 21, 3427-3441.

140. T. Okamoto, J. Sugiyama and T. Itoh, Wood research: bulletin of the Wood Research Institute Kyoto University, 1996, 83, 27-29.

141. 2013.

142. H. Yuan, Y. Nishiyama, M. Wada and S. Kuga, Biomacromolecules, 2006, 7, 696-700.

143. W. Helbert, Y. Nishiyama, T. Okano and J. Sugiyama, Journal of structural biology, 1998, 124, $42-50$.

144. H. M. Kim, S. G. Wi, S. Jung, Y. Song and H.-J. Bae, Bioresource Technol., 2015, 175, 128134.

145. T. S. Jeong, C. H. Choi, J. Y. Lee and K. K. Oh, Bioresource Technol., 2012, 116, 435-440.

146. Y.-B. Seo, Y.-W. Lee, C.-H. Lee and H.-C. You, Bioresource Technol., 2010, 101, 25492553.

147. A. Mihranyan, J. Appl. Polym. Sci., 2011, 119, 2449-2460.

148. C. Campano, A. Balea, A. Blanco and C. Negro, Cellulose, 2016, 23, 57-91.

149. S. M. Keshk, Journal of Bioprocessing \& Biotechniques, 2014, DOI: 10.4172/21559821.1000150.

150. Y. Huang, C. Zhu, J. Yang, Y. Nie, C. Chen and D. Sun, Cellulose, 2014, 21, 1-30.

151. J. V. Kumbhar, J. M. Rajwade and K. M. Paknikar, Applied microbiology and biotechnology, 2015, 99, 6677-6691.

152. Q. Cheng, S. Wang and Q. Han, J. Appl. Polym. Sci., 2010, 115, 2756-2762.

153. X. Sun, F. Xu, R. Sun, P. Fowler and M. Baird, Carbohyd. Res., 2005, 340, 97-106.

154. Y. S. Koo, Y. S. Wang, S. H. You and H. D. Kim, J. Appl. Polym. Sci., 2002, 85, 1634-1643.

155. T. Saito, R. Kuramae, J. Wohlert, L. A. Berglund and A. Isogai, Biomacromolecules, 2012, 14, 248-253.

156. K. Nakashima, J. Sugiyama and N. Satoh, Marine genomics, 2008, 1, 9-14.

157. Y. Van Daele, J.-F. Revol, F. Gaill and G. Goffinet, Biology of the Cell, 1992, 76, 87-96.

158. F. Bettaieb, R. Khiari, A. Dufresne, M. F. Mhenni and M. N. Belgacem, Carbohyd. Polym., 2015, 123, 99-104.

159. D. L. Arvizu-Higuera, Y. E. Rodríguez-Montesinos, J. I. Murillo-Álvarez, M. Muñoz-Ochoa and G. Hernández-Carmona, Journal of applied phycology, 2008, 20, 515-519.

160. N.-H. Kim, W. Herth, R. Vuong and H. Chanzy, Journal of structural biology, 1996, 117, 195-203. 
161. J. Miller, Cellulose nanomaterials production-state of the industry, http://www.tappinano.org/media/1114/cellulose-nanomaterials-production-state-of-theindustry-dec-2015.pdf, (accessed 11-11-2016, 2016).

162. D. Bondeson, A. Mathew and K. Oksman, Cellulose, 2006, 13, 171-180.

163. S. Beck-Candanedo, M. Roman and D. G. Gray, Biomacromolecules, 2005, 6, 1048-1054.

164. X. M. Dong, J.-F. Revol and D. G. Gray, Cellulose, 1998, 5, 19-32.

165. A. A. Al-Dulaimi and W. Wanrosli, J. Polym. Environ., 2016, DOI: 10.1007/s10924-0160798-z, 1-11.

166. M. A. S. Azizi Samir, F. Alloin and A. Dufresne, Biomacromolecules, 2005, 6, 612-626.

167. C. H. Lemke, R. Y. Dong, C. A. Michal and W. Y. Hamad, Cellulose, 2012, 19, 1619-1629.

168. E. d. M. Teixeira, C. R. d. Oliveira, L. H. Mattoso, A. C. Corrêa and P. D. Paladin, Polímeros, 2010, 20, 264-268.

169. J. Geboers, S. Van de Vyver, K. Carpentier, P. Jacobs and B. Sels, Chemical Communications, 2011, 47, 5590-5592.

170. Y. Liu, H. Wang, G. Yu, Q. Yu, B. Li and X. Mu, Carbohyd. Polym., 2014, 110, 415-422.

171. T. Q. Hu, R. Hashaikeh and R. M. Berry, Cellulose, 2014, 21, 3217-3229.

172. L. Chen, J. Zhu, C. Baez, P. Kitin and T. Elder, Green Chemistry, 2016, 18, 3835-3843

173. H. Abdul Khalil, A. Bhat and A. I. Yusra, Carbohyd. Polym., 2012, 87, 963-979.

174. T. Saito and A. Isogai, Colloids and Surfaces A: Physicochemical and Engineering Aspects, 2006, 289, 219-225.

175. Z.-Y. Qin, G. Tong, Y. F. Chin and J.-C. Zhou, BioResources, 2011, 6, 1136-1146.

176. Y. Okita, T. Saito and A. Isogai, Biomacromolecules, 2010, 6, 1696-1700.

177. M. Visanko, H. Liimatainen, J. A. Sirviö, J. P. Heiskanen, J. Niinimäki and O. Hormi, Biomacromolecules, 2014, 15, 2769-2775.

178. J. Zhang, B. Zhang, J. Zhang, L. Lin, S. Liu and P. Ouyang, Biotechnology advances, 2010, 28, 613-619.

179. Z. Man, N. Muhammad, A. Sarwono, M. A. Bustam, M. V. Kumar and S. Rafiq, J. Polym. Environ., 2011, 19, 726-731.

180. J. Mao, A. Osorio-Madrazo and M.-P. Laborie, Cellulose, 2013, 20, 1829-1840.

181. J. Miao, Y. Yu, Z. Jiang and L. Zhang, Cellulose, 2016, 23, 1209-1219.

182. J. Lazko, T. Sénéchal, N. Landercy, L. Dangreau, J.-M. Raquez and P. Dubois, Cellulose, 2014, 21, 4195-4207.

183. M. E. Vallejos, M. D. Zambon, M. C. Area and A. A. da Silva Curvelo, Green Chemistry, 2012, 14, 1982-1989.

184. A. V. Bandura and S. N. Lvov, Journal of physical and chemical reference data, 2006, 35, 1530 .

185. Y. Tang, S. Yang, N. Zhang and J. Zhang, Cellulose, 2014, 21, 335-346. 
186. N. Wang, E. Ding and R. Cheng, Polymer, 2007, 48, 3486-3493.

187. A. A. Oun and J.-W. Rhim, Carbohyd. Polym., 2015, 134, 20-29.

188. A. Hirai, O. Inui, F. Horii and M. Tsuji, Langmuir, 2008, 25, 497-502.

189. Y. Peng, D. J. Gardner and Y. Han, Cellulose, 2012, 19, 91-102.

190. J. Han, C. Zhou, Y. Wu, F. Liu and Q. Wu, Biomacromolecules, 2013, 14, 1529-1540.

191. X. Xu, F. Liu, L. Jiang, J. Zhu, D. Haagenson and D. P. Wiesenborn, ACS applied materials \& interfaces, 2013, 5, 2999-3009.

192. R. D. Kalita, Y. Nath, M. E. Ochubiojo and A. K. Buragohain, Colloids Surf. B Biointerfaces, 2013, 108, 85-89.

193. M. Salajková, L. A. Berglund and Q. Zhou, Journal of Materials Chemistry, 2012, 22, 1979819805.

194. W. P. F. Neto, J.-L. Putaux, M. Mariano, Y. Ogawa, H. Otaguro, D. Pasquini and A. Dufresne, RSC Adv., 2016, 6, 76017-76027.

195. B. Anwar, B. Bundjali and I. M. Arcana, Procedia Chemistry, 2015, 16, $279-284$.

196. E. Csiszar, P. Kalic, A. Kobol and E. de Paulo Ferreira, Ultrasonics Sonochemistry, 2016, 31, 473-480.

197. W. Hamad, The Canadian Journal of Chemical Engineering, 2006, 84, 513-519.

198. W. Ding, L. Calabri, X. Chen, K. M. Kohlhaas and R. S. Ruoff, Compos. Sci. Technol., 2006, 66, $1112-1124$.

199. Z. Hosseinidoust, M. N. Alam, G. Sim, N. Tufenkji and T. G. van de Ven, Nanoscale, 2015, 7, 16647-16657.

200. R. Moriana, F. Vilaplana and M. Ek, Carbohyd. Polym., 2016, 139, 139-149.

201. X. An, Y. Wen, D. Cheng, X. Zhu and Y. Ni, Cellulose, 2016, 23, 2409-2420.

202. E. Kalita, B. Nath, F. Agan, V. More and P. Deb, Ind. Crop. Prod., 2015, 65, 550-555.

203. A. M. Barbosa, E. Robles, J. S. Ribeiro, R. G. Lund, N. L. Carreño and J. Labidi, Materials, 2016, 9, 1002.

204. X. Liu, H.-Z. Dong and H.-X. Hou, Advance Journal of Food Science and Technology, 2015, 7, 466-473.

205. H. Kargarzadeh, I. Ahmad, I. Abdullah, A. Dufresne, S. Y. Zainudin and R. M. Sheltami, Cellulose, 2012, 19, 855-866.

206. S. Zainuddin, I. Ahmad and H. Kargarzadeh, Composite Interfaces, 2013, 20, 189-199.

207. F. Luzi, E. Fortunati, A. Jiménez, D. Puglia, D. Pezzolla, G. Gigliotti, J. Kenny, A. Chiralt and L. Torre, Ind. Crop. Prod., 2016, 93, 276-289.

208. R. E. Abraham, C. S. Wong and M. Puri, Materials, 2016, 9, 562.

209. K. Pacaphol and D. Aht-Ong, Journal of Cleaner Production, 2017, 142, 1283-1295.

210. L. Camargo, S. Pereira, A. Correa, C. Farinas, J. Marconcini and L. Mattoso, Bioenerg. Res., 2016, 9, 894-906. 
211. P. Kampeerapappun, Journal of Metals, Materials and Minerals, 2015, 25, 19-26.

212. L. A. D. S. Costa, A. F. Fonseca, F. V. Pereira and J. I. Druzian, Cellulose Chemistry and Technology, 2015, 49, 127-133.

213. R. M. dos Santos, W. P. F. Neto, H. A. Silvério, D. F. Martins, N. O. Dantas and D. Pasquini, Ind. Crop. Prod., 2013, 50, 707-714.

214. D. Hammiche, A. Boukerrou, H. Djidjelli, Y. Grohens, A. Bendahou and B. Seantier, Journal of Adhesion Science and Technology, 2016, 30, 1899-1912.

215. Q. Lu, W. Lin, L. Tang, S. Wang, X. Chen and B. Huang, J. Mater. Sci., 2015, 50, 611-619.

216. E. Fortunati, F. Luzi, A. Jiménez, D. Gopakumar, D. Puglia, S. Thomas, J. Kenny, A. Chiralt and L. Torre, Carbohyd. Polym., 2016, 149, 357-368.

217. F. Kallel, F. Bettaieb, R. Khiari, A. García, J. Bras and S. E. Chaabouni, Ind. Crop. Prod., 2016, 87, 287-296.

218. M. Mohamed, W. Salleh, J. Jaafar, S. Asri and A. Ismail, RSC Adv., 2015, 5, 29842-29849.

219. Y. Li, Y. Liu, W. Chen, Q. Wang, Y. Liu, J. Li and H. Yu, Green Chemistry, 2016, 18, 10101018.

220. Q. Lu, L. Tang, F. Lin, S. Wang, Y. Chen, X. Chen and B. Huang, Cellulose, 2014, 21, 34973506.

221. N. Savadekar, V. Karande, N. Vigneshwaran, P. Kadam and S. Mhaske, Applied Nanoscience, 2015, 5, 281-290.

222. S. B. A. Hamid, S. K. Zain, R. Das and G. Centi, Carbohyd. Polym., 2016, 138, 349-355. 
Fig. 1 llustration of the annual number of scientific publications since 2006, using the search terms "Cellulose nanocrystals/cellulose nanowhisker and composite". Data analysis completed using Scopus search system on 22 November, 2016.

Fig. 2 Schematic representation of the chemical structure and intra-, inter-molecular hydrogen bonds in cellulose (reprinted with permission from ref. ${ }^{19}$, Copyright (C) Elsevier Limited).

Fig. 3 Hierarchical structure of cellulose and its nanomaterials types. The combined figure is reproduced from several figures appearing in ref. ${ }^{19,92,191,192}$ with permission.

Fig. 4 Transmission electron microscope (TEM) images of cellulose nanocrystals derived from (a) softwood ${ }^{193}$, (b) hardwood ${ }^{194}$, (c) tomato peel ${ }^{134}$, (d) Calotropis procera $^{31}$, (e) oil palm ${ }^{64}$, (f) red algae ${ }^{40}$, (g) sea plant ${ }^{158}$, (h) tunicate ${ }^{103}$, (i) bactirial cellulose ${ }^{195}$. (reprinted with permission from ref. ${ }^{103}$, Copyright ()$^{\circ}$ The American Chemical Society; ref. ${ }^{193,}{ }^{194}$, Copyright (C) The Royal Society of Chemistry; ref. ${ }^{31,40,64,134,158,195}$, Copyright (C) Elsevier Limited).

Fig. 5 Scheme for cellulose isolation from tomato peels. All yield values were based on original TP in \%. Reprinted with permission from ref. ${ }^{134}$, Copyright (C) 2015, Elsevier Limited.

Fig. 6 Scheme of the tunicate cellulose isolation from Halocynthia roretzi. Reprinted from ref. ${ }^{139}$ with permission. Copyright (C) 2014, Springer Science.

Fig. 7 (a) Schematic representation of the different steps used to produce CNCs (or NCC) from bleached cotton fabric. Reprinted from ref. ${ }^{196}$ with permission. Copyright (C) 2015, Elsevier Limited; (b) The overall procedure for the preparation of CNCs (or NCC) by using phosphotungstic acid (HPW). Reprinted from ref. ${ }^{170}$ with permission. Copyright (C) 2014, Elsevier Limited; (c) Simplified structure of a cellulose microfibril with crystalline segments irregularly interrupted by disordered segments. Disordered segments can be selectively targeted with controlled acid hydrolysis, leading to the isolation of cellulose nanocrystals. Adapted from ref. ${ }^{22}$ with permission. Copyright (C) 2016, The Royal Society of Chemistry.

Fig. 8 Schematic route for fabricating carboxylated CNCs. Reprinted from ref. ${ }^{29}$ with permission. Copyright (C) The American Chemical Society.

Fig. 9 One-pot preparation of hydrophobic CNCs in TBAA/DMAc with acetic hydride (upper), and the more typical route (lower) with permission. Reprinted from ref. ${ }^{181}$ Copyright $($ C Springer Science.

Fig. 10 Schematic of possible formation mechanism of the lamellar geometry and the alignment of ultrafine fibers during the freeze-drying process. Reprinted from ref. ${ }^{190}$ with permission. Copyright (C) The American Chemical Society. 


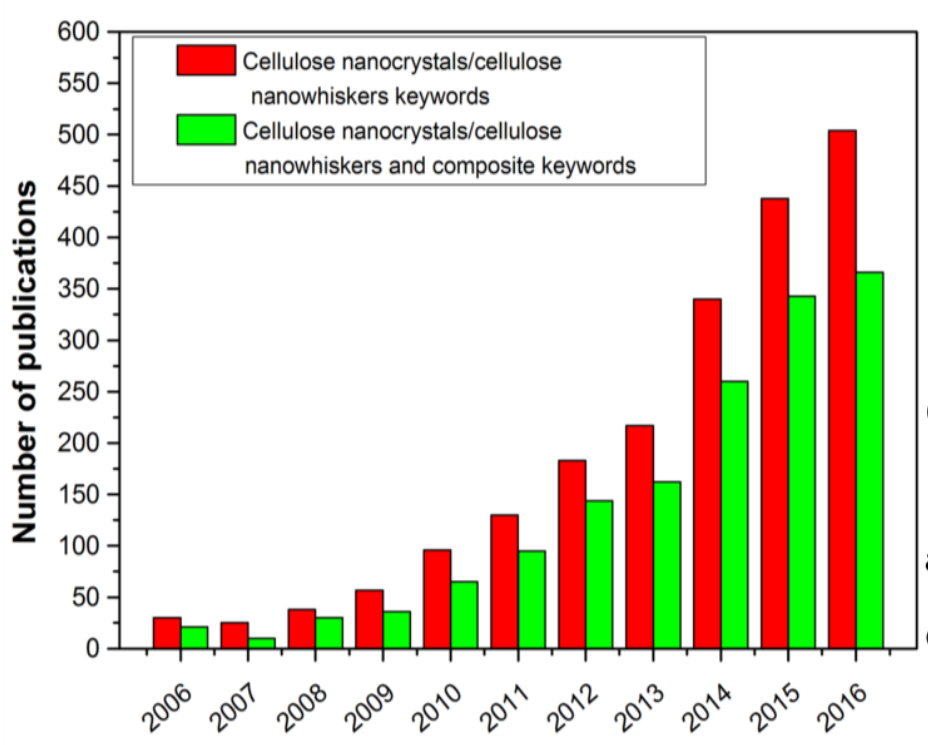

Publication year

Fig. 1 
1258

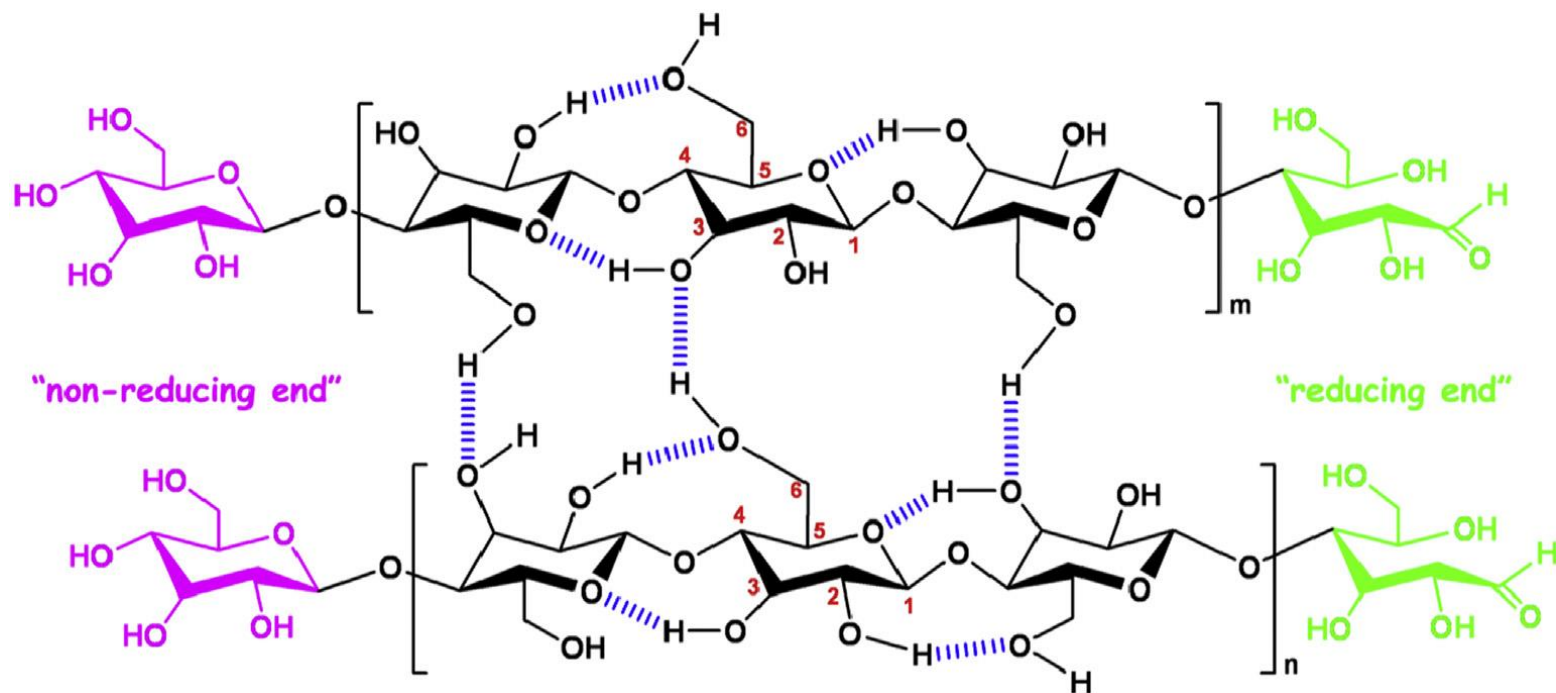

1259

Fig. 2

1260

1261

1262

1263

1264

1265

1266

1267

1268

1269 


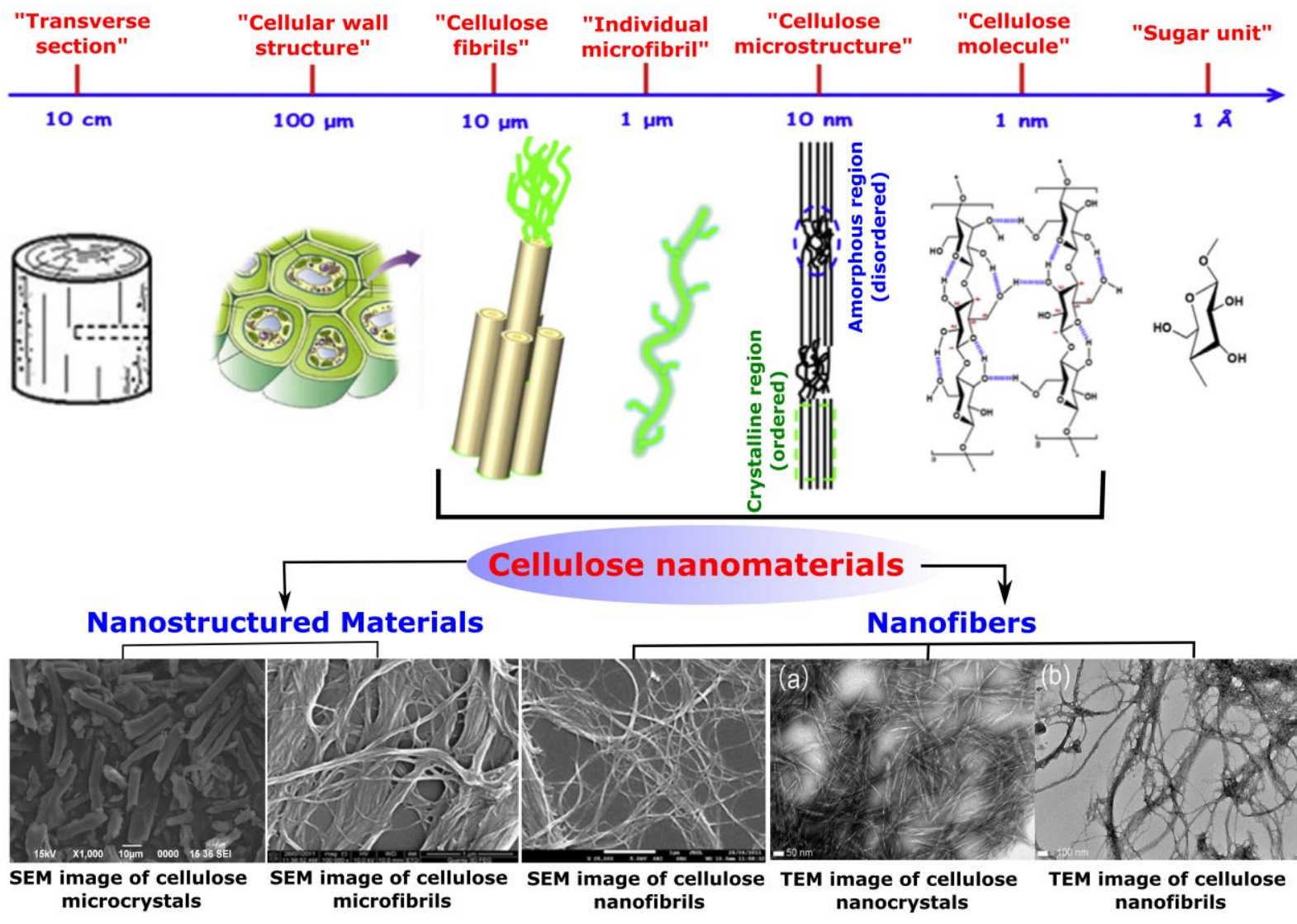

Fig. 3

1272

1273

1274

1275

1276

1277

1278

1279

1280

1281

1282

1283 

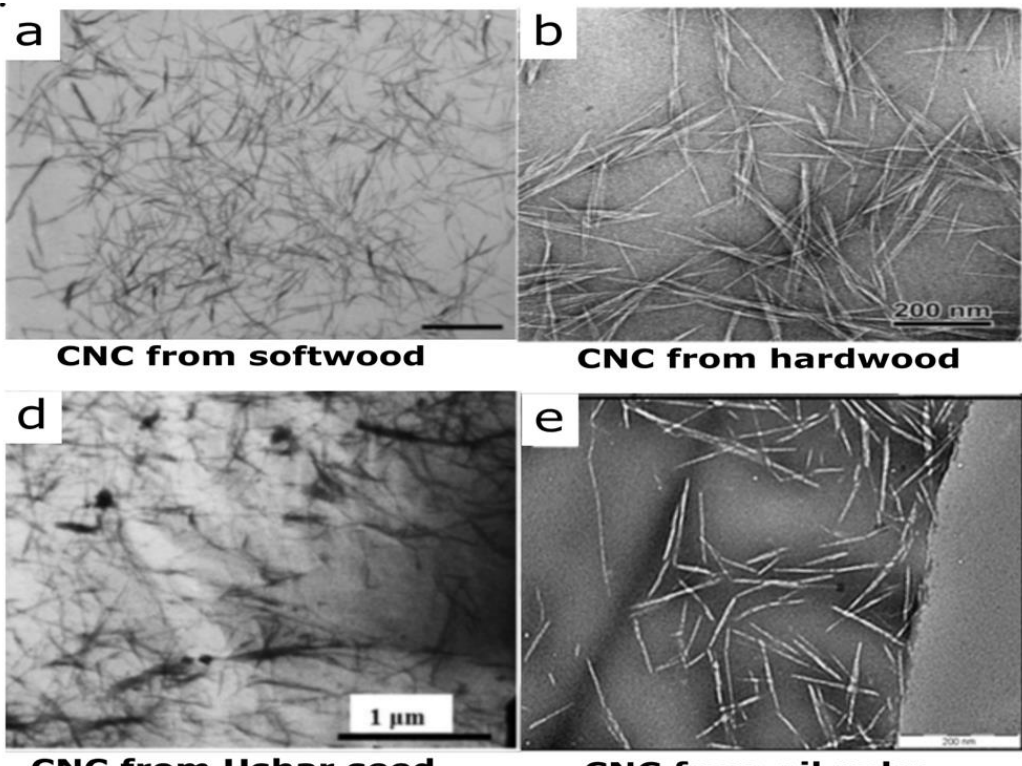

C

CNC from Ushar seed CNC from hardwood
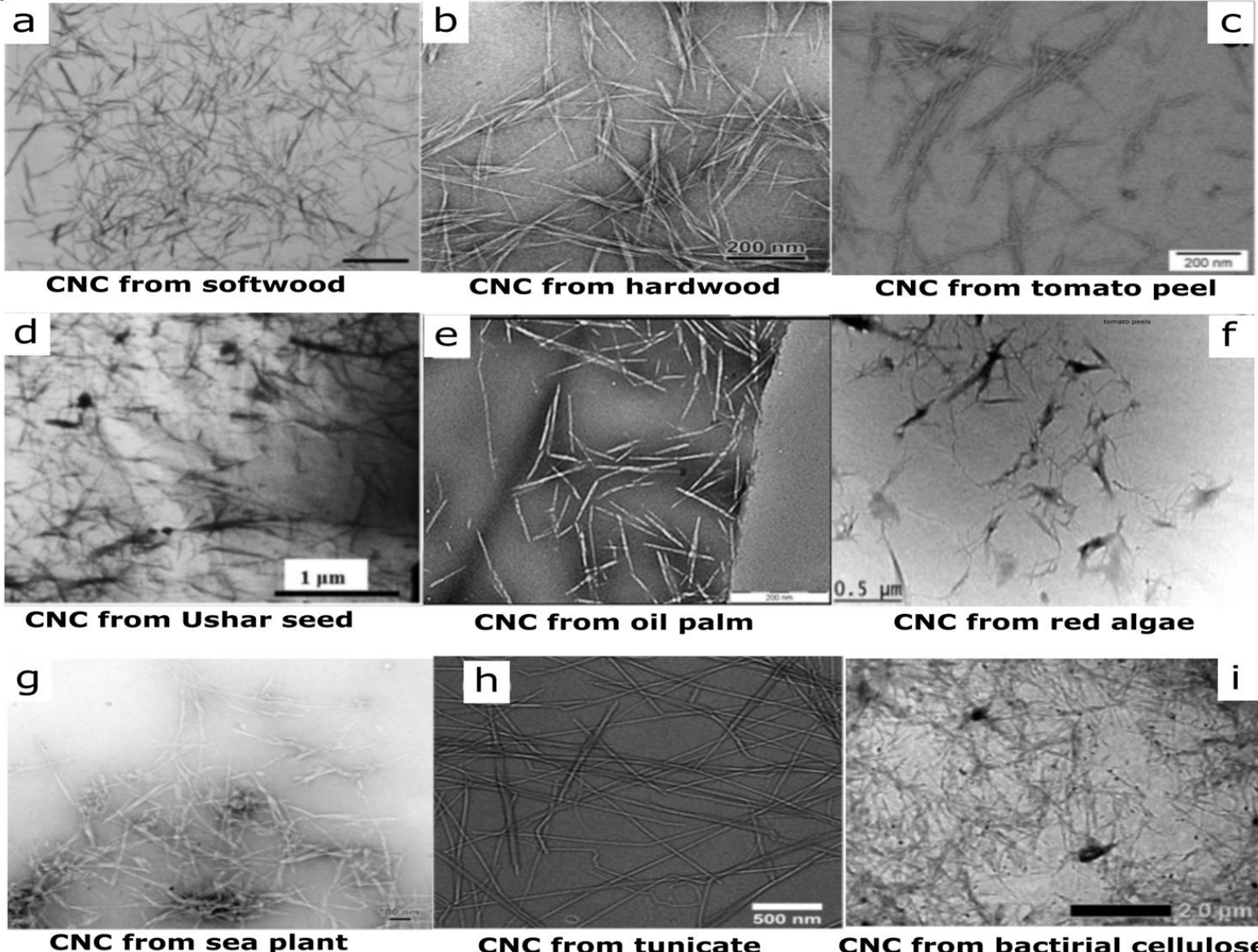

CNC from oil palm CNC from red algae

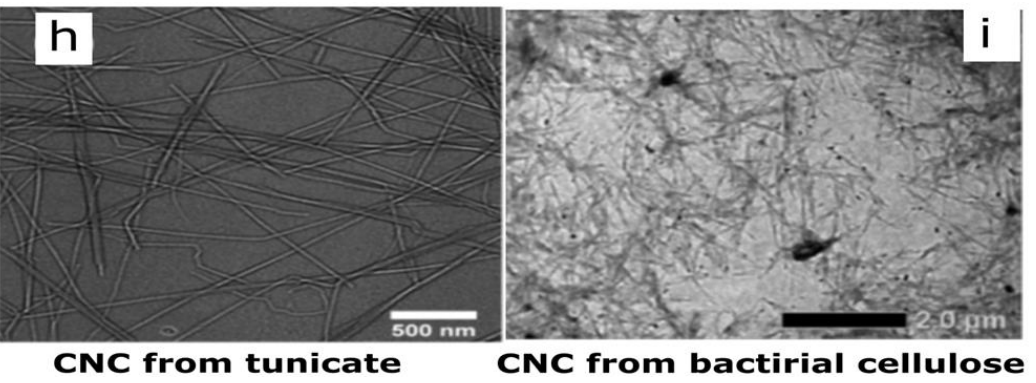

Fig. 4 


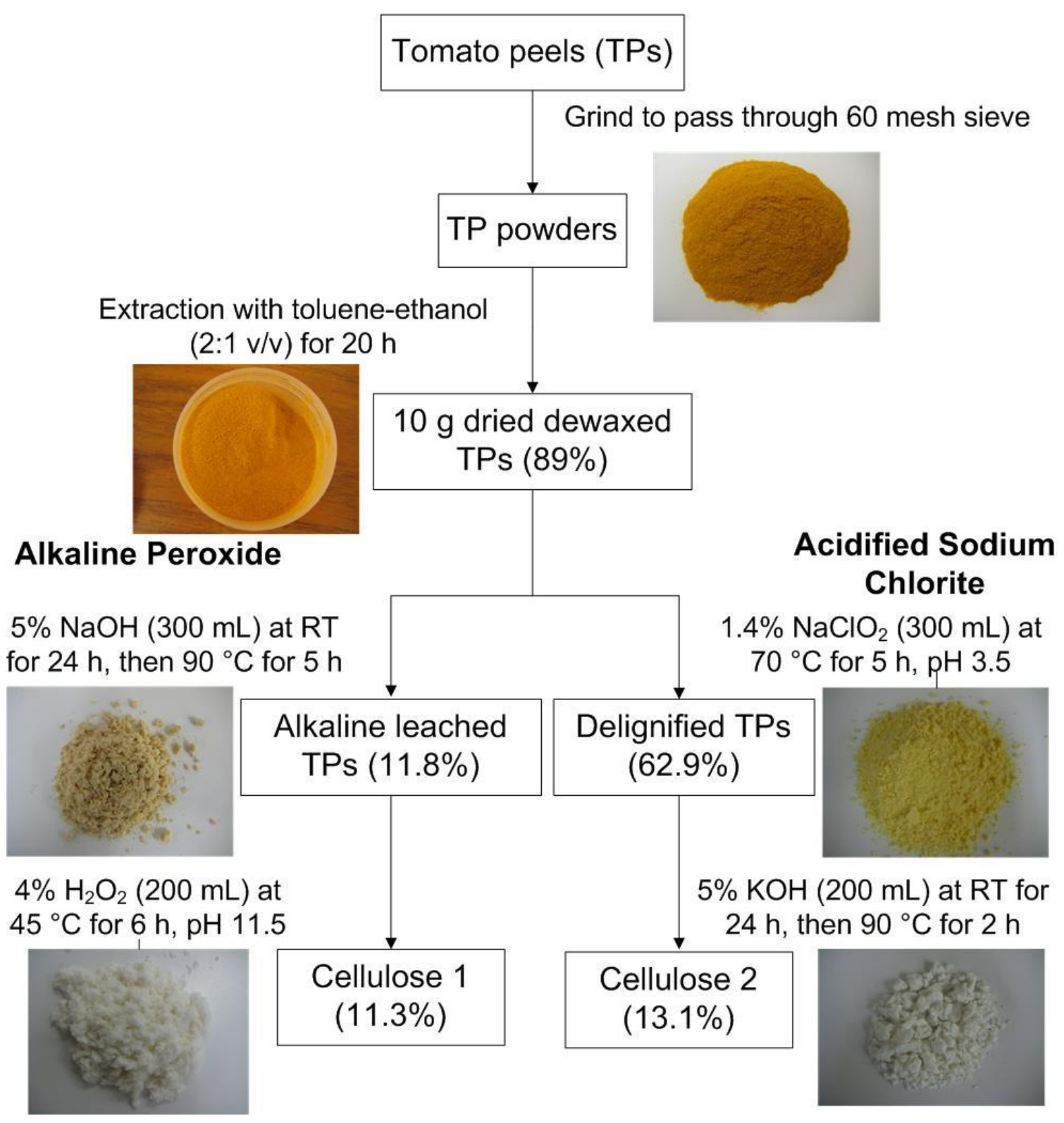

Fig. 5 


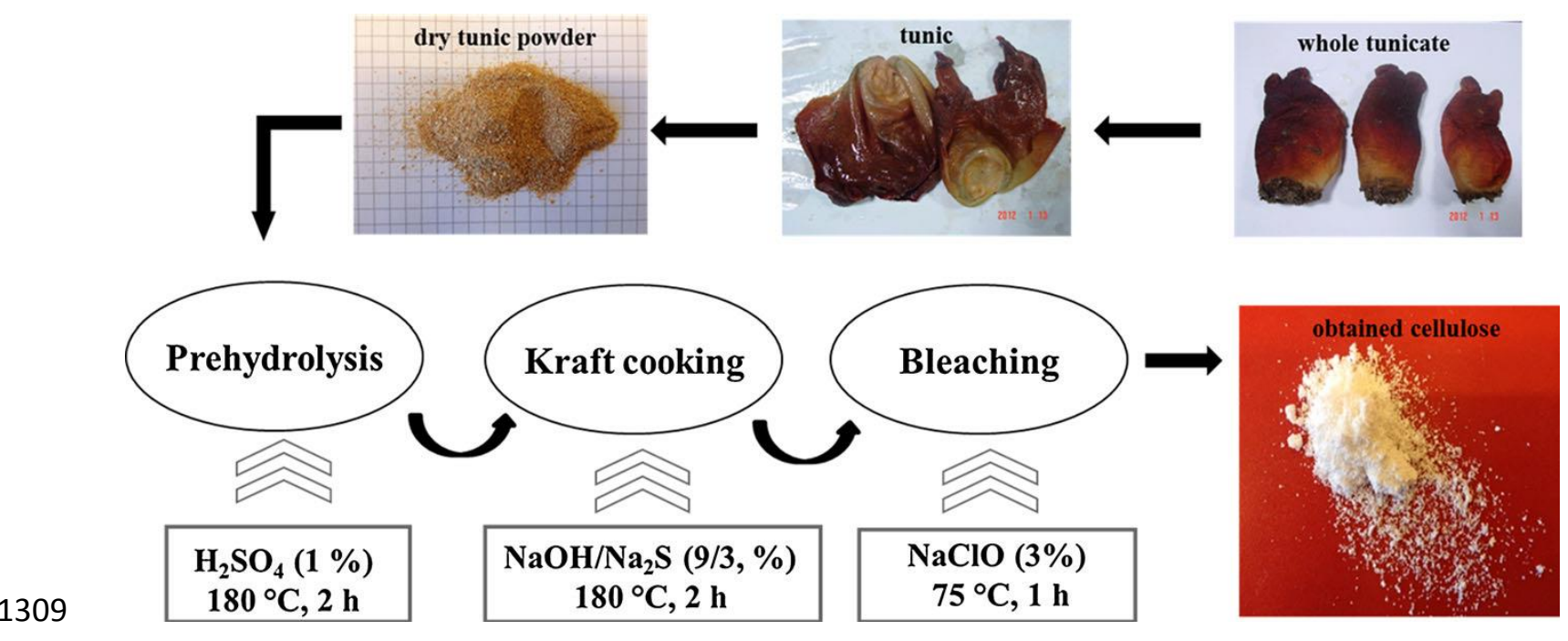

1310

Fig. 6

1311

1312

1313

1314

1315

1316

1317

1318

1319

1320

1321

1322

1323

1324

1325

1326

1327

1328 


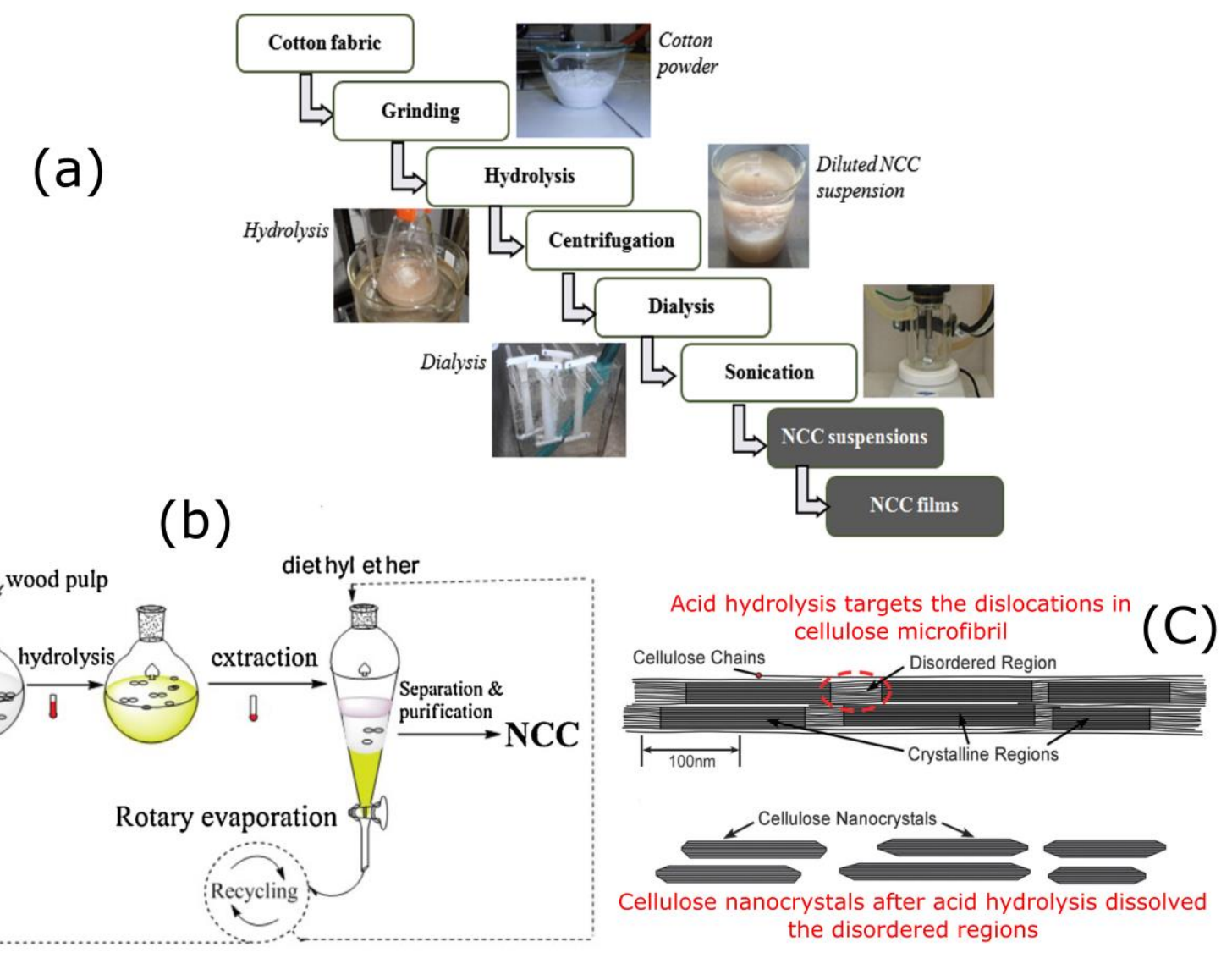




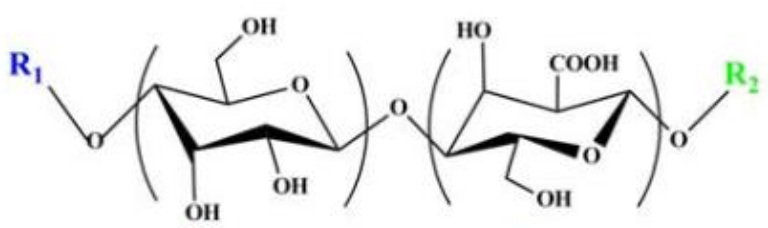

\section{Path 1}

$80^{\circ} \mathrm{C}$

Path 2

Acid dissociation and MCC hydrolysis

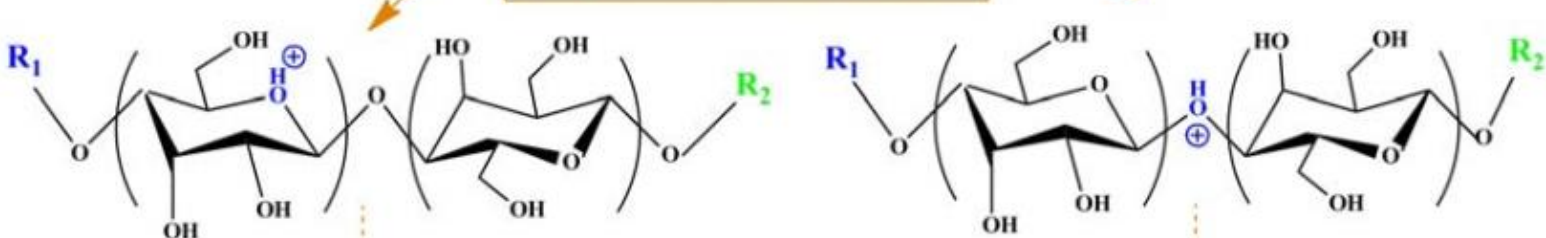

Slow $\mathrm{H}_{2} \mathrm{O}$

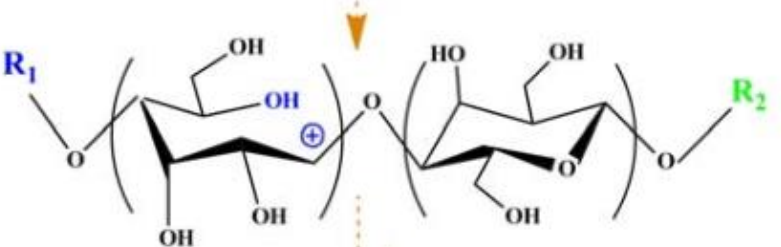

Slow $\mathrm{H}_{2} \mathrm{O}$
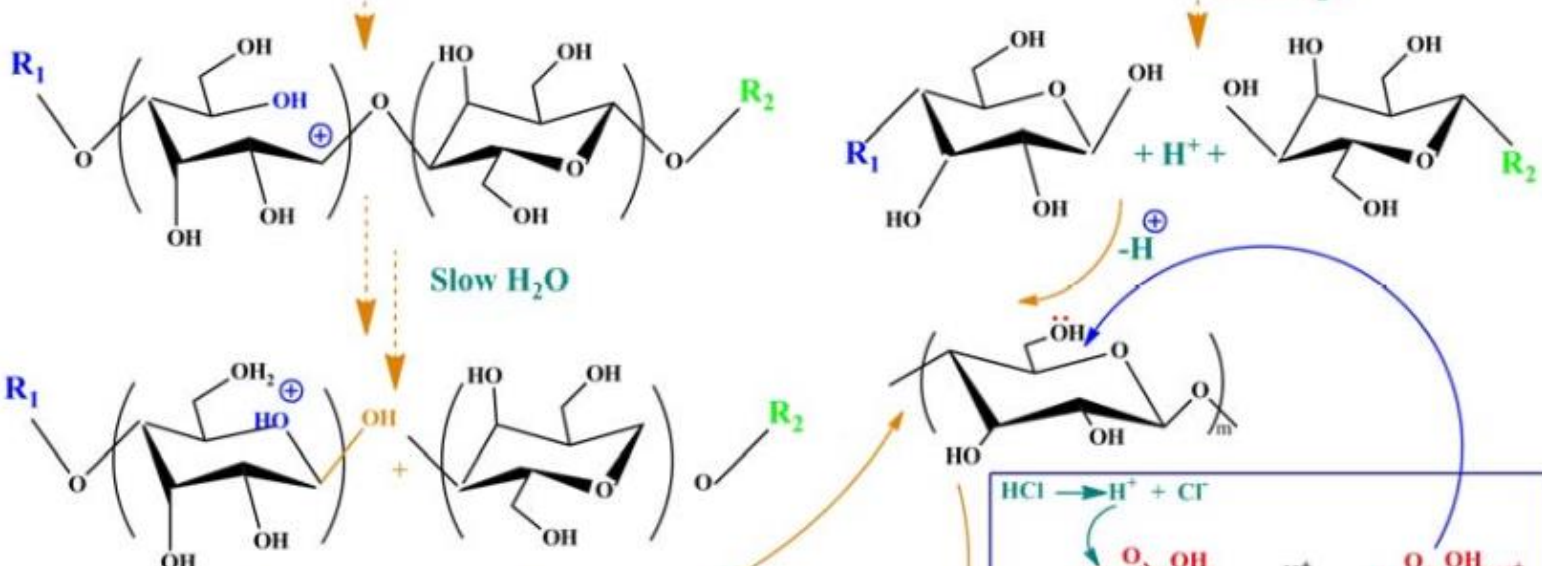

Fig. 8 


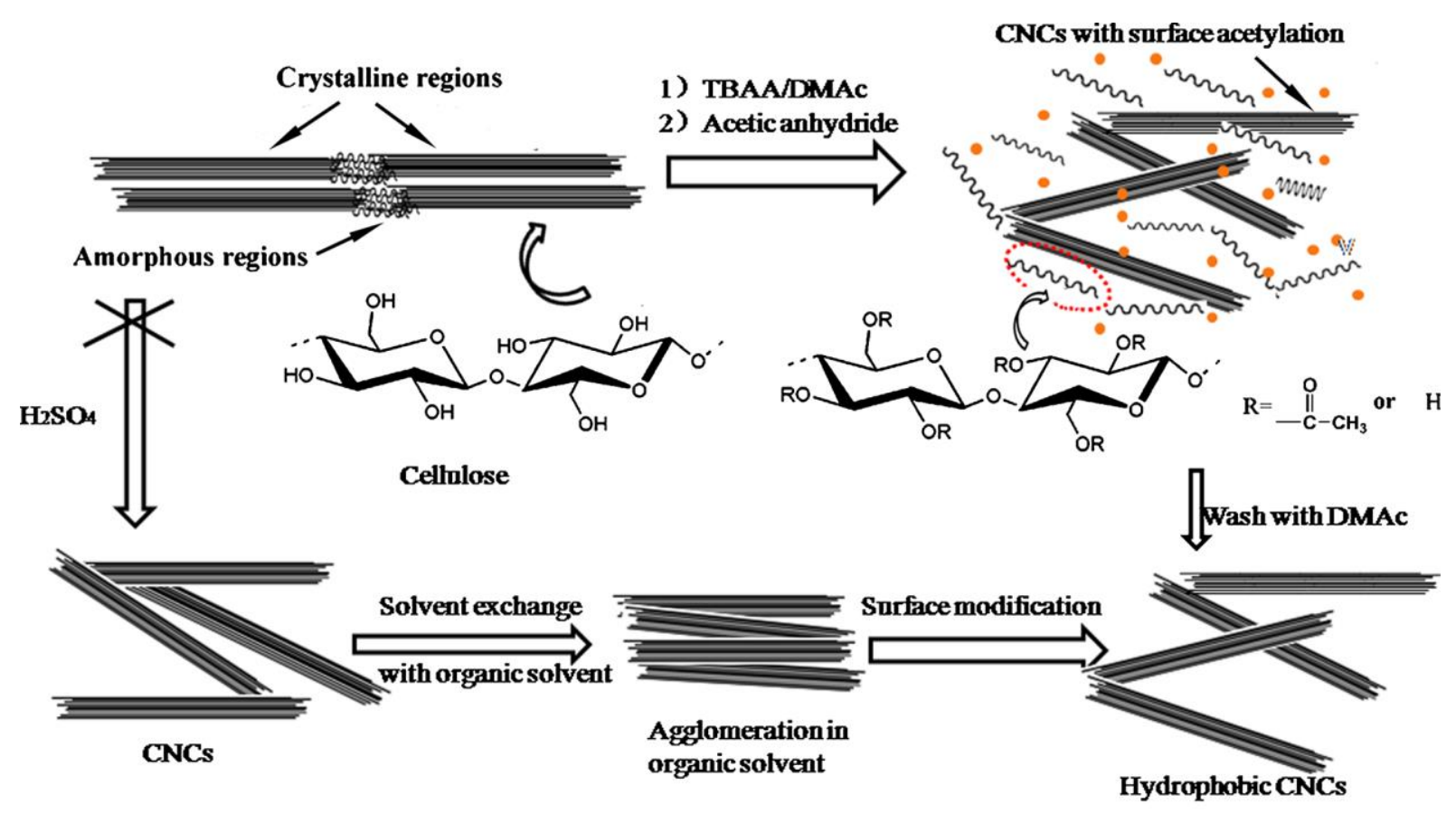

Fig. 9 


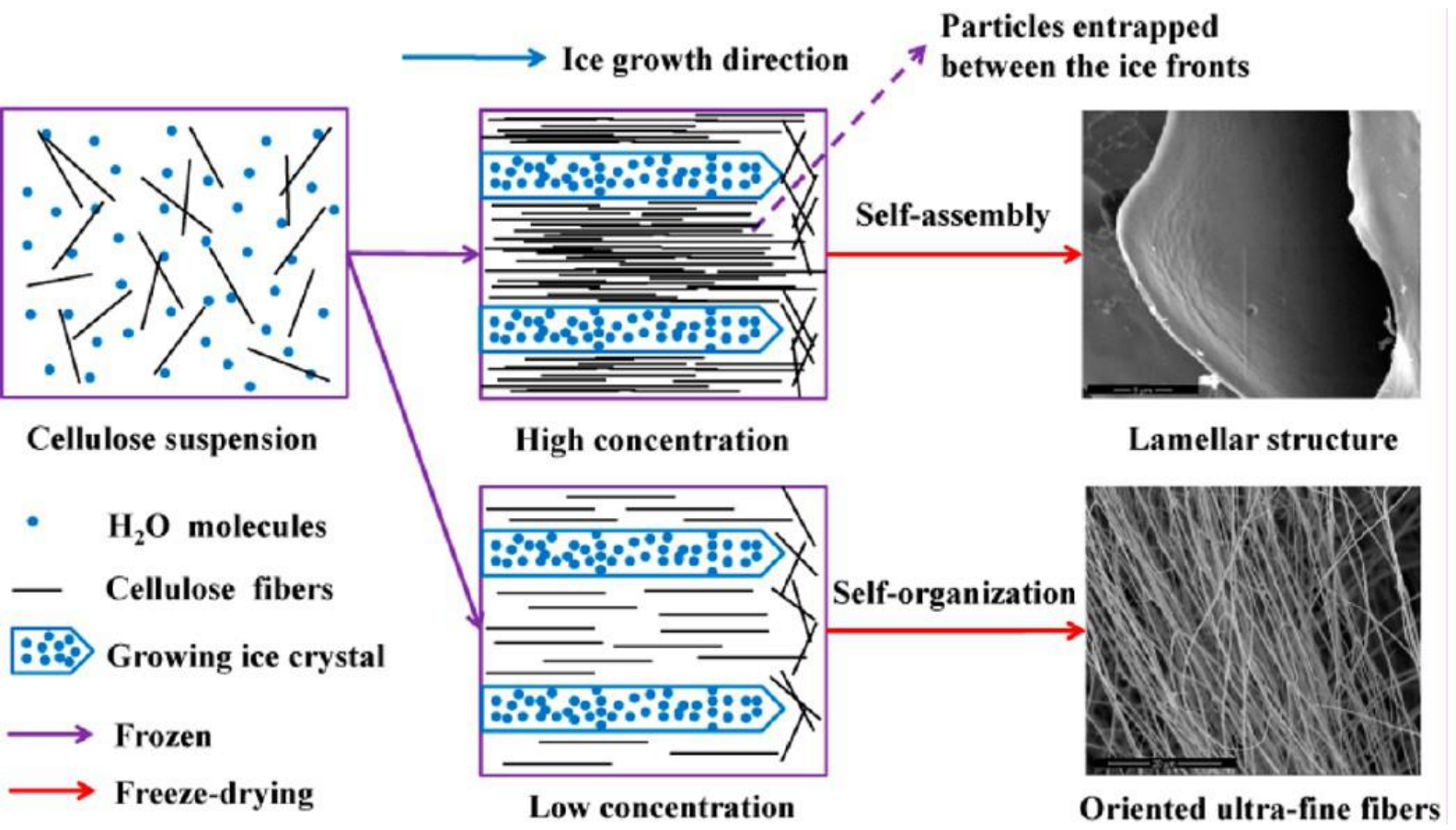

Fig. 10

1355

1356

1357

1358

1359

1360

1361

1362

1363

1364

1365

1366

1367

1368

1369

1370 
1371 Table 1 Mechanical properties of cellulose nanocrystals and other reinforcement materials.

\begin{tabular}{|c|c|c|c|c|}
\hline Material & $\sigma(\mathrm{MPa})$ & $E(\mathrm{GPa})$ & $\rho\left(\mathrm{g} \mathrm{cm}^{-3}\right)$ & References \\
\hline $\mathrm{CNC}$ & $7500-7700$ & $110-220$ & 1.6 & Moon et $a l .(2011)^{22}$ \\
\hline Glass fiber & 4800 & 86 & 2.5 & Kim et al. $(2015)^{76}$ \\
\hline 302 Stainless steel & 1280 & 210 & 7.8 & Hamad (2006) ${ }^{197}$ \\
\hline Softwood kraft pulp & 700 & 20 & 1.5 & Hamad (2006) ${ }^{197}$ \\
\hline Carbon fiber & 4100 & 210 & 1.8 & Moon et $a l .(2011)^{22}$ \\
\hline Boron nanowhiskers & $2000-8000$ & $250-360$ & - & Ding et al. (2006) \\
\hline Aluminum & 330 & 71 & 2.7 & Brinchi et al. $(2013)^{35}$ \\
\hline Carbon nanotubes & $11000-63000$ & $270-950$ & - & Moon et al. $(2011)^{22}$ \\
\hline Kevlar KM2 Fiber & 3880 & 88 & 1.4 & Brinchi et al. $(2013)^{35}$ \\
\hline \multicolumn{5}{|c|}{$\sigma=$ tensile strength, $E=$ elastic modulus in axial direction, $\rho=$ density } \\
\hline
\end{tabular}


Table 2 Various lignocellulosic sources of cellulose nanocrystals fibers.

\begin{tabular}{|c|c|c|}
\hline Source & & References \\
\hline \multirow[t]{3}{*}{ Woody plants } & Softwood & $\begin{array}{l}\text { Hosseinidoust et } \text { al. }(2015)^{199}, \text { Moriana et } \\
\text { al. }(2016)^{200} \text {, An et al. }(2016)^{201}\end{array}$ \\
\hline & Hardwood & $\begin{array}{l}\text { Du et al. }(2016)^{38} \text {, Mao et } a l .(2015)^{57} \text {, Liu et } a l . \\
(2014)^{170} \text {, Chen et } a l .(2016){ }^{172}\end{array}$ \\
\hline & Sawdust wastes & Kalita et al. $(2015)^{202}$ \\
\hline \multirow{13}{*}{$\begin{array}{l}\text { Non-woody plants and } \\
\text { agricultural residues }\end{array}$} & Flax Fibers & Mtibe et $a l .(2015)^{131}$, Barbosa et $a l .(2016)^{203}$ \\
\hline & Oil palm & $\begin{array}{l}\text { Haafiz et } a l .(2014)^{116} \text {, Dungani et al. }(2016)^{117} \text {, } \\
\text { Lamaming et al. }(2017)^{27}\end{array}$ \\
\hline & Peanut Shells & Liu et $a l .(2015)^{204}$ \\
\hline & Potato peel & Chen et al. $(2012)^{119}$, Jiang and Hsieh $(2015)^{134}$ \\
\hline & Jute & Cao et $a l .(2012)^{62}$, Kasyapi et $a l .(2013)^{120}$ \\
\hline & Kenaf & $\begin{array}{l}\text { Kargarzadeh et } a l .(2012)^{205}, \text { Zainuddin et al. } \\
(2013)^{206}\end{array}$ \\
\hline & Hemp & $\begin{array}{l}\text { Luzi et } a l .(2016)^{207} \text {, Abraham et } a l .(2016)^{208} \text {, } \\
\text { Pacaphol et al. }(2017)^{209}\end{array}$ \\
\hline & Bagasse & Camargo et al. $(2016)^{210}$, de Oliveira et al. $(2016)^{39}$ \\
\hline & Corn & $\begin{array}{l}\text { Silvério et al. }(2013)^{126}, \text { Kampeerapappun } \\
(2015)^{211}, \text { Costa et } a l .(2015)^{212}\end{array}$ \\
\hline & $\begin{array}{l}\text { Pineapple leaf and } \\
\text { coir }\end{array}$ & dos Santos et $a l .(2013)^{213}$, Deepa et $a l .(2015)$ \\
\hline & Alfa & Hammiche et al. $(2016)^{214}$ \\
\hline & Bamboo & Chen et $a l .(2011)^{127}$, Lu et $a l .(2015)^{215}$ \\
\hline & Sunflower & Fortunati et $a l .(2016)^{216}$ \\
\hline
\end{tabular}

Garlic straw residues $\quad$ Kallel et al. $(2016)^{217}$ 
Table 3 Different processing conditions used for the production of CNCs.

\begin{tabular}{|c|c|c|c|c|c|}
\hline Main process & Raw material & Purification & Treatment Procedure & Post-treatment & Reference \\
\hline \multirow[t]{9}{*}{$\begin{array}{l}\text { Acid } \\
\text { hydrolysis }\end{array}$} & $\begin{array}{l}\text { Microcrystalline } \\
\text { cellulose }\end{array}$ & No & $\begin{array}{l}\text { Dilution, cation exchange resin hydrolysis, } \\
\text { ultrasonication }\end{array}$ & $\begin{array}{l}\text { Filtration, rinsing, } \\
\text { centrifugation }\end{array}$ & $\begin{array}{l}\text { Tang et } a l \text {. } \\
(2011)^{47}\end{array}$ \\
\hline & Pineapple leaf & $\begin{array}{l}\text { Grinding, Sodium hydroxide, } \\
\text { acetic acid, sodium chlorite } \\
\text { treatments }\end{array}$ & Grinding, $\mathrm{H}_{2} \mathrm{SO}_{4} 64 \%$ at $45^{\circ} \mathrm{C}$ hydrolysis, dilution & $\begin{array}{l}\text { Centrifugation, dialysis, } \\
\text { ultrasonication }\end{array}$ & $\begin{array}{l}\text { dos Santos et } \\
\text { al. }(2013)^{213}\end{array}$ \\
\hline & \multirow[t]{2}{*}{$\begin{array}{l}\text { Whatman filter } \\
\text { paper }\end{array}$} & Blending & $4 \mathrm{~N} \mathrm{HCl}$ solution at $100{ }^{\circ} \mathrm{C}$ for $120 \mathrm{~min}$ & $\begin{array}{l}\text { Centrifugation, dialysis, } \\
\text { ultrasonication }\end{array}$ & \multirow[t]{2}{*}{$\begin{array}{l}\text { Camarero } \\
\text { Espinosa et al. } \\
(2013)^{46}\end{array}$} \\
\hline & & Blending & $\mathrm{H}_{3} \mathrm{PO}_{4} 85 \%$ at $60{ }^{\circ} \mathrm{C}$ hydrolysis, dilution & $\begin{array}{l}\text { Centrifugation, dialysis, } \\
\text { ultrasonication, } \\
\text { lyophilization }\end{array}$ & \\
\hline & White coir & $\begin{array}{l}\text { Organosolv process, alkaline- } \\
\text { peroxide bleaching }\end{array}$ & $\mathrm{H}_{2} \mathrm{SO}_{4} 30 \%$ at $60{ }^{\circ} \mathrm{C}$ hydrolysis, dilution & $\begin{array}{l}\text { Centrifugation, dialysis, } \\
\text { ultrasonication }\end{array}$ & $\begin{array}{l}\text { Nascimento et } \\
\text { al. }(2014){ }^{138}\end{array}$ \\
\hline & $\begin{array}{l}\text { Pseudostems of } \\
\text { banana plants }\end{array}$ & $\begin{array}{l}\text { Soxhlet extraction, alkali } \\
\text { treatment, bleaching with } \mathrm{H}_{2} \mathrm{O}_{2} \\
\text { and acetic acid }\end{array}$ & Dilution, blending, $\mathrm{H}_{2} \mathrm{SO}_{4}$ at $50{ }^{\circ} \mathrm{C}$ hydrolysis & $\begin{array}{l}\text { Centrifugation, dialysis, } \\
\text { lyophilization }\end{array}$ & $\begin{array}{l}\text { Mueller et al. } \\
(2014)^{132}\end{array}$ \\
\hline & $\begin{array}{l}\text { Bleached } \\
\text { hardwood pulp }\end{array}$ & No & $\begin{array}{l}\text { Phosphotungstic acid }\left(\mathrm{H}_{3} \mathrm{PW}_{12} \mathrm{O}_{40}\right) \text { hydrolysis at } 0 \\
{ }^{\circ} \mathrm{C} \text {, extraction with diethyl ether }\end{array}$ & $\begin{array}{l}\text { Decantation, ethanol } \\
\text { precipitation, } \\
\text { washing/centrifugation } \\
\text { cycles }\end{array}$ & $\begin{array}{l}\text { Liu et } a l \text {. } \\
(2014))^{170}\end{array}$ \\
\hline & $\begin{array}{l}\text { Recycled } \\
\text { Newspaper }\end{array}$ & $\begin{array}{l}\text { Grinding, Sodium hydroxide, } \\
\text { sodium chlorite treatments at } \\
125^{\circ} \mathrm{C}\end{array}$ & $\mathrm{H}_{2} \mathrm{SO}_{4} 65 \%$ at $45^{\circ} \mathrm{C}$ hydrolysis, dilution & $\begin{array}{l}\text { Centrifugation, dialysis, } \\
\text { sonication }\end{array}$ & $\begin{array}{l}\text { Mohamed et } \\
\text { al. }(2015)^{218}\end{array}$ \\
\hline & Posidonia & Sodium hydroxide, acetic acid, & $\mathrm{H}_{2} \mathrm{SO}_{4}$ at $55^{\circ} \mathrm{C}$ hydrolysis & Centrifugation, dialysis, & Bettaieb et $a l$. \\
\hline
\end{tabular}




\begin{tabular}{|c|c|c|c|c|c|}
\hline & oceanica & sodium chlorite treatments & & ultrasonication & $(2015)^{158}$ \\
\hline & $\begin{array}{l}\text { Bleached kraft } \\
\text { eucalyptus dry lap } \\
\text { pulp }\end{array}$ & $\begin{array}{l}\text { Soaking in water, } \\
\text { disintegrating, drying }\end{array}$ & $\begin{array}{l}\text { Anhydrous organic acid hydrolysis at } 90-120^{\circ} \mathrm{C} \text {, } \\
\text { dilution, filtration }\end{array}$ & $\begin{array}{l}\text { Washing, centrifugation, } \\
\text { dialysis }\end{array}$ & $\begin{array}{l}\text { Chen et al. } \\
(2016)^{172}\end{array}$ \\
\hline & Sisal fibers & Grinding, bleaching & Grinding, $\mathrm{H}_{2} \mathrm{SO}_{4} 60 \%$ at $55^{\circ} \mathrm{C}$ hydrolysis, dilution & Centrifugation, dialysis & $\begin{array}{l}\text { Mariano et al. } \\
(2016)^{133}\end{array}$ \\
\hline & $\begin{array}{l}\text { Bleached } \\
\text { eucalyptus kraft } \\
\text { pulp }\end{array}$ & No & $\begin{array}{l}\text { Anhydrous ferric chloride -catalyzed formic acid } \\
\text { hydrolysis at } 95{ }^{\circ} \mathrm{C}\end{array}$ & $\begin{array}{l}\text { Centrifugation, dilution, } \\
\text { distillation, dissolution in } \\
\text { water, precipitation }\end{array}$ & $\begin{array}{l}\text { Du et } a l \text {. } \\
(2016)^{38}\end{array}$ \\
\hline & $\begin{array}{l}\text { Commercial } \\
\text { microcrystalline } \\
\text { cellulose }\end{array}$ & No & Citric/hydrochloric acid hydrolysis & $\begin{array}{l}\text { Washing, centrifugation, } \\
\text { freeze drying }\end{array}$ & $\begin{array}{l}\text { Yu et } a l \text {. } \\
(2016)^{29}\end{array}$ \\
\hline & Bacterial cellulose & $\begin{array}{l}\text { Washing, homogenization, } \\
\text { drying, grinding }\end{array}$ & $\mathrm{H}_{2} \mathrm{SO}_{4} / \mathrm{HCl}$ mixture at $45^{\circ} \mathrm{C}$, dilution & $\begin{array}{l}\text { Centrifugation, dialysis, } \\
\text { ultrasonication }\end{array}$ & $\begin{array}{l}\text { Vasconcelos } \\
\text { et } a l .(2017)^{26}\end{array}$ \\
\hline $\begin{array}{l}\text { Mechanical } \\
\text { treatment }\end{array}$ & $\begin{array}{l}\text { Microcrystalline } \\
\text { cellulose }\end{array}$ & No & $\begin{array}{l}\text { Swilling in water, ultrasonication at power of } 1500 \\
\mathrm{~W}\end{array}$ & centrifugation, freeze drying & $\begin{array}{l}\text { Li et } a l \text {. } \\
(2012)^{54}\end{array}$ \\
\hline & $\begin{array}{l}\text { Microcrystalline } \\
\text { cellulose }\end{array}$ & No & $\begin{array}{l}\text { Dispersion in water, ultrasonication for } 50 \text { minutes } \\
\text { at an output of } 500 \mathrm{~W} \text {, frequency of } 20 \mathrm{kHz}\end{array}$ & Decantation, freeze drying & $\begin{array}{l}\text { Amin et al. } \\
(2015)^{52}\end{array}$ \\
\hline & & & Dispersion in water, high-energy bead milling & & \\
\hline & Wood & $\begin{array}{l}\text { Ethanol solvothermal } \\
\text { treatment, alkaline hydrogen } \\
\text { peroxide treatment }\end{array}$ & Soaking in distilled water, ultrasonication & Washing, drying & $\begin{array}{l}\text { Li et } a l \text {. } \\
(2016)^{219}\end{array}$ \\
\hline $\begin{array}{l}\text { Oxidation } \\
\text { method }\end{array}$ & Jute fibers & $\begin{array}{l}\text { Grinding, Sodium hydroxide, } \\
\text { washing, dimethylsulfoxide } \\
\text { treatments }\end{array}$ & Treatment with TEMPO/NaClO/NaBr system & $\begin{array}{l}\text { Centrifugation, sonication, } \\
\text { drying }\end{array}$ & $\begin{array}{l}\text { Cao et } a l \text {. } \\
(2012)^{62}\end{array}$ \\
\hline
\end{tabular}




\begin{tabular}{|c|c|c|c|c|c|}
\hline & $\begin{array}{l}\text { Bleached kraft } \\
\text { hardwood pulp }\end{array}$ & No & $\begin{array}{l}\text { lithium chloride-assisted sodium metaperiodate } \\
\text { oxidation at } 75{ }^{\circ} \mathrm{C}\end{array}$ & $\begin{array}{l}\text { Washing, dispersion, } \\
\text { homogenization }\end{array}$ & $\begin{array}{l}\text { Visanko et } a l \text {. } \\
(2014)^{177}\end{array}$ \\
\hline \multirow[t]{4}{*}{$\begin{array}{l}\text { Enzymatic } \\
\text { hydrolysis }\end{array}$} & Cotton fibers & $\begin{array}{l}\text { Hydrochloric acid } \\
\text { hydrolysis }(4 \mathrm{~N} \mathrm{HCl})\end{array}$ & Fermentation & $\begin{array}{l}\text { Centrifugation, } \\
\text { ultrafiltration, freeze drying }\end{array}$ & $\begin{array}{l}\text { Satyamurthy } \\
\text { et al. (2011) }\end{array}$ \\
\hline & Cotton fibers & $\begin{array}{l}\text { DMSO and } \mathrm{NaOH} \text {, ultrasonic } \\
\text { treatments }\end{array}$ & $\begin{array}{l}\text { Treatment with buffer solution of cellulose at } 45 \\
{ }^{\circ} \mathrm{C}\end{array}$ & Centrifugation & $\begin{array}{l}\text { Chen et } a l \text {. } \\
(2012)^{50}\end{array}$ \\
\hline & $\begin{array}{l}\text { Flax and Hemp } \\
\text { fibers }\end{array}$ & $\begin{array}{l}\text { Washing, drying, } \\
\text { chemical/ultrasonic/microwave } \\
\text { pretreatment }\end{array}$ & $\begin{array}{l}\text { Treatment in acetate buffer supplemented with } \\
\text { endoglucanase and incubated in a shaker at } 50{ }^{\circ} \mathrm{C}\end{array}$ & $\begin{array}{l}\text { Centrifugation, rinsing, } \\
\text { ultrafiltration, freeze drying }\end{array}$ & $\begin{array}{l}\text { Xu et } a l . \\
(2013)\end{array}$ \\
\hline & Bleached kraft pulp & $\begin{array}{l}\text { Pre-soaking in water, grinding, } \\
\text { centrifugation }\end{array}$ & $\begin{array}{l}\text { Treatment with commercial enzymes or termite } \\
\text { cellulose and incubated at intervals from } 6-72 \mathrm{~h} \text { at } \\
35^{\circ} \mathrm{C} \text {. }\end{array}$ & Washing, lyophilization & $\begin{array}{l}\text { Anderson et } \\
\text { al. }(2014)^{48}\end{array}$ \\
\hline \multirow[t]{4}{*}{$\begin{array}{l}\text { Ionic liquid } \\
\text { treatment }\end{array}$} & $\begin{array}{l}\text { Cotton cellulose } \\
\text { fibers }\end{array}$ & Drying at $105^{\circ} \mathrm{C}$ during $24 \mathrm{~h}$ & $\begin{array}{l}\text { Treatment with 1-butyl-3-methylimidazolium } \\
\text { chloride in presence } \mathrm{H}_{2} \mathrm{SO}_{4} \text { of at } 80{ }^{\circ} \mathrm{C} \text {, dilution }\end{array}$ & $\begin{array}{l}\text { Washing, centrifugation, } \\
\text { freeze drying }\end{array}$ & $\begin{array}{l}\text { Lazko et } a l \\
(2014) \\
182\end{array}$ \\
\hline & $\begin{array}{l}\text { Bleached wood } \\
\text { kraft pulp }\end{array}$ & Oven drying & $\begin{array}{l}\text { Swelling in pure 1-butyl-3- } \\
\text { methylimidazoliumhydrogen sulfate at room } \\
\text { temperature followed by the incorporation of } \\
\text { deionized water }\end{array}$ & $\begin{array}{l}\text { Centrifugation, dialysis, } \\
\text { freeze drying }\end{array}$ & $\begin{array}{l}\text { Mao et } a l \text {. } \\
(2015)^{57}\end{array}$ \\
\hline & $\begin{array}{l}\text { Angelim vermelho } \\
\text { wood }\end{array}$ & $\begin{array}{l}\text { Grinding, dewaxing, washing, } \\
\text { drying }\end{array}$ & $\begin{array}{l}\text { Treatment with 1-Ethyl-3-methylimidazolium } \\
\text { acetate at } 60^{\circ} \mathrm{C} \text {, centrifugation }\end{array}$ & $\begin{array}{l}\text { Washing, DMSO treatment, } \\
\text { dissolving, drying }\end{array}$ & $\begin{array}{l}\text { Abushammala } \\
\text { et al. }(2015)^{58}\end{array}$ \\
\hline & Pure cotton & No & $\begin{array}{l}\text { Swelling in 1-butyl-3-methylimidazolium chloride } \\
\text { and 1-(4-sulfobutyl)-3-methylimidazolium } \\
\text { hydrogen sulfate followed by quenching by adding } \\
\text { cold water. }\end{array}$ & $\begin{array}{l}\text { Washing/centrifugation } \\
\text { cycles, freeze drying }\end{array}$ & $\begin{array}{l}\text { Lazko et } a l \text {. } \\
(2016)^{55}\end{array}$ \\
\hline
\end{tabular}




\begin{tabular}{|c|c|c|c|c|c|}
\hline & $\begin{array}{l}\text { Hardwood } \\
\text { pulpboard }\end{array}$ & No & $\begin{array}{l}\text { Treatment with solvent system } \\
\text { tetrabutylammonium acetate/dimethylacetamide in } \\
\text { conjunction with acetic acid at } 65^{\circ} \mathrm{C}\end{array}$ & $\begin{array}{l}\text { Washing, centrifugation, } \\
\text { drying }\end{array}$ & $\begin{array}{l}\text { Miao et } a l \text {. } \\
(2016)^{181}\end{array}$ \\
\hline $\begin{array}{l}\text { Subcritical } \\
\text { water } \\
\text { hydrolysis }\end{array}$ & $\begin{array}{l}\text { Commercial } \\
\text { microcrystalline } \\
\text { cellulose }\end{array}$ & No & $\begin{array}{l}\text { Water hydrolysis at } 120^{\circ} \mathrm{C} \text { and pressure of } 20.3 \\
\mathrm{MPa}\end{array}$ & $\begin{array}{l}\text { Filtration with a Pyrex® } \\
\text { Buchner funnel with glass } \\
\text { fritted disc, dialysis, } \\
\text { ultrasonication }\end{array}$ & $\begin{array}{l}\text { Novo et } a l \text {. } \\
(2015 \& 2016) \\
32,59\end{array}$ \\
\hline \multirow[t]{6}{*}{$\begin{array}{l}\text { Combined } \\
\text { processes }\end{array}$} & Filter paper & Cut into pieces & $\begin{array}{l}\text { Treatment with sulfuric acid solution assisted by } \\
\text { simultaneously ultrasonic wave and microwave }\end{array}$ & $\begin{array}{l}\text { Dilution, centrifugation, } \\
\text { drying }\end{array}$ & $\begin{array}{l}\text { Lu et } a l \text {. } \\
(2013)^{68}\end{array}$ \\
\hline & Bamboo pulp sheet & Cut into pieces, pulping & $\begin{array}{l}\text { Ultrasonication-assisted Ferric chloride -catalyzed } \\
\text { hydrolysis, dilution }\end{array}$ & Washing, centrifugation & $\begin{array}{l}\text { Lu et } a l \text {. } \\
(2014)^{220}\end{array}$ \\
\hline & $\begin{array}{l}\text { Old corrugated } \\
\text { container material }\end{array}$ & $\begin{array}{l}\text { Disintegration, soaking in } \\
\text { water, pulping, sodium } \\
\text { hydroxide pretreatment }\end{array}$ & $\begin{array}{l}\text { Phosphoric acid hydrolysis, washing, enzymatic } \\
\text { hydrolysis, }\end{array}$ & $\begin{array}{l}\text { Ultrasonication, } \\
\text { centrifugation, dialysis, } \\
\text { freeze drying }\end{array}$ & $\begin{array}{l}\text { Tang et } a l \text {. } \\
(2015)^{67}\end{array}$ \\
\hline & Cotton linters & No & $\begin{array}{l}\text { Acid hydrolysis and subsequent processing in a } \\
\text { high-pressure homogenizer. }\end{array}$ & $\begin{array}{l}\text { Washing, filtration, drying, } \\
\text { dispersion }\end{array}$ & $\begin{array}{l}\text { Savadekar et } \\
\text { al. }(2015)^{221}\end{array}$ \\
\hline & $\begin{array}{l}\text { Commercial } \\
\text { microcrystalline } \\
\text { cellulose }\end{array}$ & No & $\begin{array}{l}\text { Dispersion in water, ultrasonication combined with } \\
\text { tungstophosphoric acid }\end{array}$ & $\begin{array}{l}\text { Extraction with diethyl } \\
\text { ether, drying }\end{array}$ & $\begin{array}{l}\text { Hamid et al. } \\
(2016)^{222}\end{array}$ \\
\hline & $\begin{array}{l}\text { Oil palm empty } \\
\text { fruit bunch } \\
\text { microcrystalline } \\
\text { cellulose }\end{array}$ & No & $\begin{array}{l}\text { Sono-assisted TEMPO-oxidation, followed by } \\
\text { sonication (mechanical treatment) }\end{array}$ & $\begin{array}{l}\text { Washing, centrifugation, } \\
\text { drying }\end{array}$ & $\begin{array}{l}\text { Rohaizo and } \\
\text { Wanrosli } \\
(2017)^{64}\end{array}$ \\
\hline
\end{tabular}




\section{For table of contents use only:}

Cellulose nanocrystals, an emergent nanomaterial, can be produced from various natural sources using different procedures such as acid hydrolysis, mechanical, enzymatic, oxidation, ionic liquid, subcritical water or combined processes.

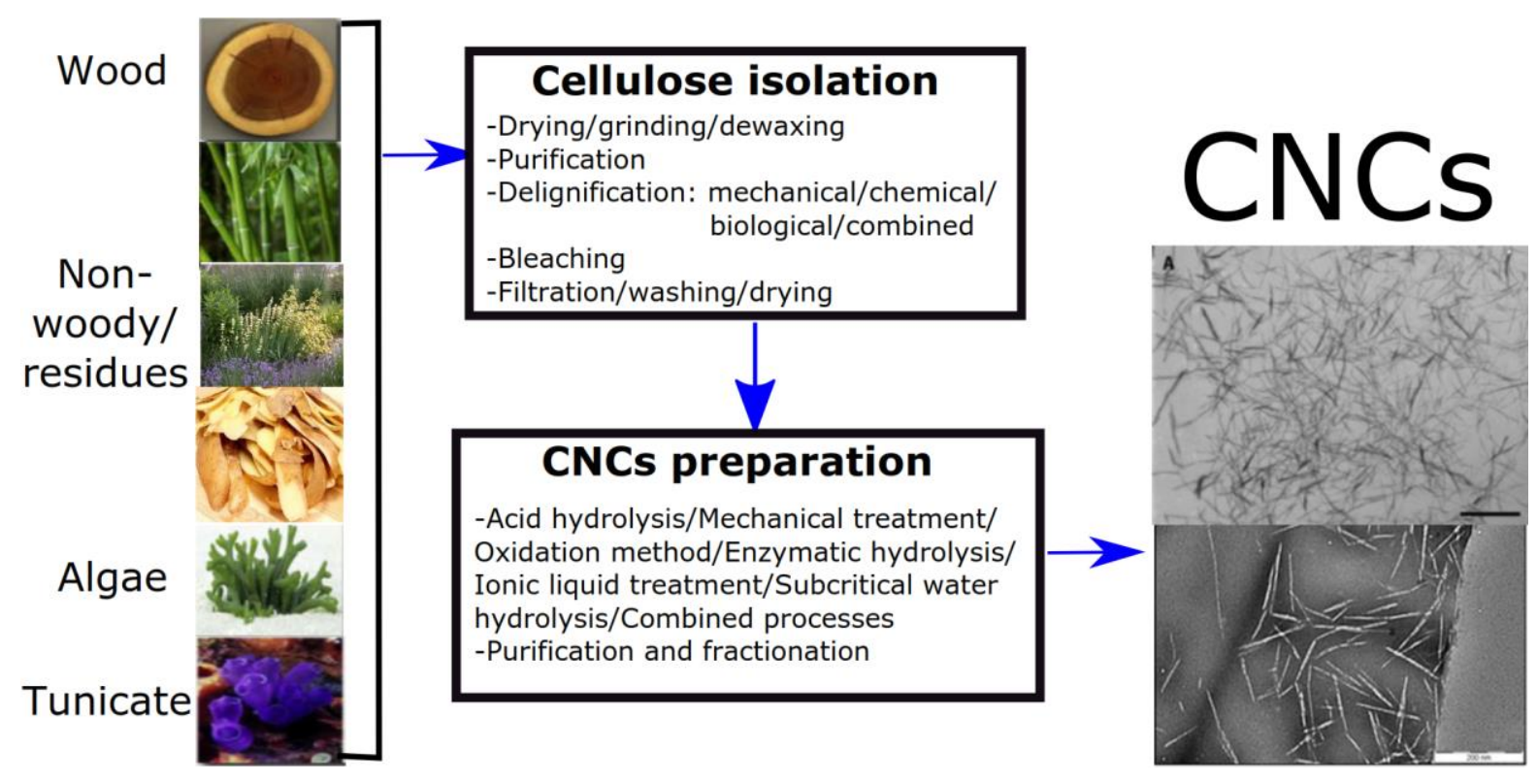


2017-01-24

Recent progress in cellulose

nanocrystals: sources and production

Trache, D.

Royal Society of Chemistry

Trache D, Hussin MH, Haafiz MM, Thakur VK, Recent progress in cellulose nanocrystals:

pÿsources and production, Nanoscale, Volume 9, Issue 5, Pages 17631786.

http://dx.doi.org/10.1039/C6NR09494E

Downloaded from Cranfield Library Services E-Repository 